\title{
The Physiological Role of Myoglobin: More than a Problem in Reaction-Diffusion Kinetics
}

\author{
JOHN A. JACQUEZ \\ Department of Physiology \\ The University of Michigan \\ Ann Arbor, Michigan 48109
}

Received 19 September 1983

\section{INTRODUCTION}

Oxygen has a very low solubility in aqueous solutions, and with rare exceptions we find that oxygen is carried in the circulation almost entirely in combination with a special oxygen-binding protein. Four main types of such proteins are found in the animal kingdom: hemoglobins, chlorocruorins, hemerythrins, and hemocyanins. The most widely distributed in the animal kingdom are the hemoglobins, which are found in all phyla. The chlorocruorins are modified hemoglobins found in only a few families of polychaete worms.

In evolutionary terms the hemoglobins are ancient molecules, and they come in many sizes. The large hemoglobins, of molecular weight around $10^{6}$, are found only in invertebrates. Generally the large molecules are found free in the plasma, whereas the small ones are packaged in cells, the red blood cells. In red cells of almost all vertebrates hemoglobin is a tetramer of two similar basic chains; for example, in adult humans the tetramer consists of two $\alpha$ and two $\beta$ chains. The monomers are of molecular weight (16-17) $\times 10^{3}$. However, another molecule, a monomeric oxygen-binding globin called tissue hemoglobin or myoglobin, is found in heart and red skeletal muscle cells. It is found in invertebrates as well as vertebrates. This review is concerned with the function of myoglobin, but brings in hemoglobin because both have been used in some of the work on facilitated diffusion of oxygen.

Myoglobin has been thought to serve as a long term and short term oxygen store [1]. In the muscles of diving mammals and birds the concentration of myoglobin is very high, giving the muscles a dark red to near-black color depending on the degree of oxygenation. In the divers it may serve as an oxygen store sufficient for a few minutes. In nondiving animals red muscles have much lower concentrations of myoglobin, and it has been suggested that the myoglobin serves as a short term store to provide oxygen 
during the contractile phase of strong rhythmic contractions; during the contractions blood flow is markedly reduced. Finally, it has been proposed that myoglobin plays its major role in facilitating the diffusion of oxygen inside muscle cells.

The work on facilitation of oxygen diffusion by myoglobin falls into two main phases. The first is the demonstration of facilitation of diffusion of oxygen across porous membranes saturated with concentrated aqueous solutions of hemoglobin or myoglobin. Accompanying this experimental work there have been intensive efforts on the analysis of the experimental results in terms of reaction-diffusion theory. It turns out to give an interesting two point boundary value problem in second order nonlinear differential equations. The second and more recent phase of this work has involved experimental efforts to demonstrate the facilitation of oxygen diffusion by myoglobin in living slices of muscle or in perfused muscles. Accompanying this work there have been a few attempts to model oxygen diffusion and the contribution of myoglobin in cylindrical tissue domains surrounding a capillary.

The biological literature up to 1970 is reviewed in the papers by Wittenberg [1] and Kreuzer [2]. Good reviews of the experimental background and mathematical approaches from a more general viewpoint, with inclusion of applications and theory in chemical engineering, are given by Schultz et al. [3] and Goddard et al. [4]. Here, I try to give what I hope is a fairly complete bibliography for the work on myoglobin since 1970 and include relevant work on hemoglobin.

\section{FACILITATED DIFFUSION THROUGH POROUS MEMBRANES}

1. BASIC EXPERIMENTS

Interest in the possible role of myoglobin and hemoglobin in facilitating diffusion of oxygen goes back to early work of Roughton [5] and the review
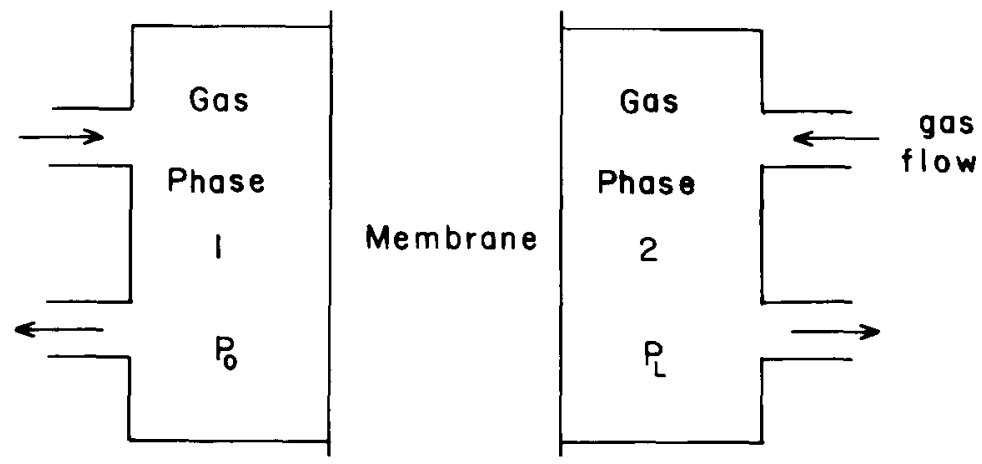

FIG. 1. Diagram of experimental arrangement for measuring steady state transfer of oxygen across porous membrane saturated with a solution of myoglobin or hemoglobin. $P_{0}$ and $P_{L}$ are partial pressures of oxygen. 
of Millikan [6]. However, the experiments that really ignited the interest in this phenomenon that led to the modern modeling work were done in the period 1956-1960 [7-11]. These involved measurement of steady state movement of oxygen across a porous membrane that contained a solution of hemoglobin or myoglobin and separated two gas phases that were flushed with gases containing different concentrations of oxygen. The basic experimental setup is shown diagrammatically in Figure 1. Figure 2 shows the total steady state flux of oxygen across such a membrane when $P_{\mathrm{O}_{2}}$ is near zero on side 2 as well as the expected diffusive flux of $\mathrm{O}_{2}$ alone. The experimental evidence that the extra or facilitated flux is due to diffusion of oxyhemoglobin or oxymyoglobin may be summarized briefly as follows:

(1) The flux is saturable in the partial pressure of $\mathrm{O}_{2}$ on side 1 .

(2) If the partial pressures on sides 1 and 2 are both raised, maintaining the gradient, so that the hemoglobin will be practically saturated at both sides of the membrane, the facilitated flux disappears.

(3) If the hemoglobin is oxidized to methemoglobin, a form which no longer binds molecular oxygen, there is no facilitated flux.

(4) The facilitated flux per unit hemoglobin or myoglobin concentration increases linearly with the diffusion coefficient of the heme-protein.

(5) If the viscosity of the medium is increased the facilitated flux decreases.

Details of the experiments supporting these conclusions may be found in

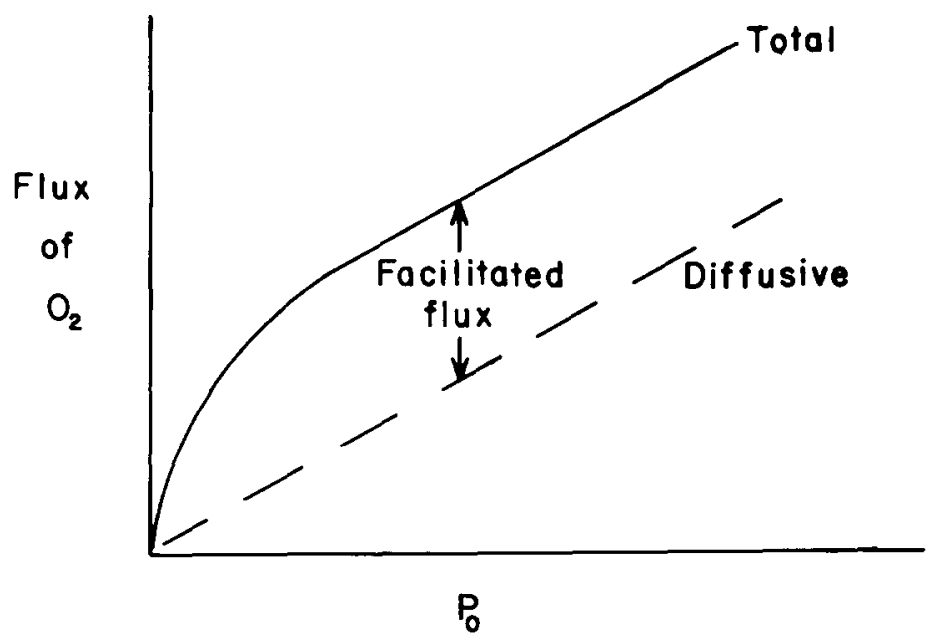

FIG. 2. Dependence of steady state oxygen flux on $P_{\mathrm{O}_{2}}$ in phase $1 . P_{\mathrm{O}_{2}}$ in chamber 2 is very low and fixed. 
Wittenberg's [1] review and the original literature cited there. Early in the game [10] it was suggested that rotation of the heme-protein molecules and transfer of oxygen between adjacent molecules might explain the facilitation, but calculations show that the contribution from rotational diffusion must be very small $[12,13]$.

\section{THE STEADY STATE EQUATIONS FOR MYOGLOBIN}

We shall concentrate on myoglobin, which has only one binding site for oxygen, so the reaction is bimolecular as in Equation (1). Let

$$
\mathrm{Mb}+\mathrm{O}_{2} \underset{k_{2}}{\stackrel{k_{1}}{\rightleftharpoons}} \mathrm{MbO}_{2},
$$

where $u, v$, and $w$ stand for the concentrations of $\mathrm{Mb}, \mathrm{MbO}_{2}$, and $\mathrm{O}_{2}$ respectively. (A glossary of symbols is given in Section VI.) For hemoglobin there are four binding sites per molecule which interact, so that the reaction equations are more involved, but in fact Equation (1) has also been used to describe facilitated diffusion in hemoglobin solutions. To develop the full time-dependent equations, look at a slab of membrane extending from depth $x$ to $x+d x$ and write the balance equation for $u, v$, and $w$ (Figure 3) to obtain Equations (2)-(4), assuming $D_{u}, D_{v}, D_{w}$ are constant:

$$
\begin{aligned}
& \frac{\partial w}{\partial t}=D_{w} \frac{\partial^{2} w}{\partial x^{2}}-k_{1} u w+k_{2} v, \\
& \frac{\partial u}{\partial t}=D_{u} \frac{\partial^{2} u}{\partial x^{2}}-k_{1} u w+k_{2} v, \\
& \frac{\partial v}{\partial t}=D_{v} \frac{\partial^{2} v}{\partial x^{2}}+k_{1} u w-k_{2} v
\end{aligned}
$$

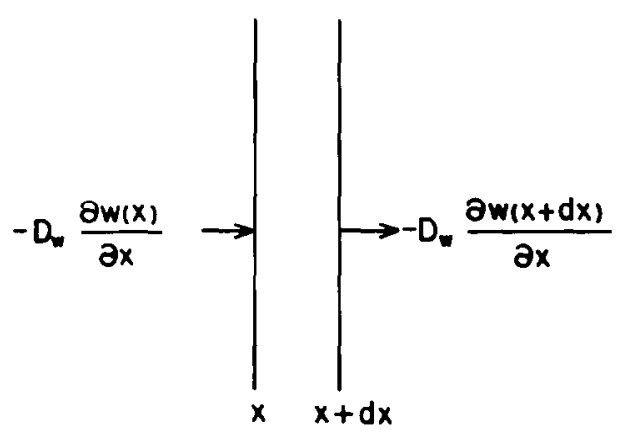

FIG. 3. Thin slice used for deriving balance equations. 
We are concerned for the moment only with the steady state. Furthermore, the oxygenated and nonoxygenated forms have the same diffusion coefficients, $D_{u}=D_{v}$. Consequently, at any point in the membrane $u+v=b$, a constant, the total concentration of myoglobin. Using that relation, the equations for the steady state become

$$
\begin{aligned}
D_{w} \frac{d^{2} w}{d x^{2}} & =k_{1}(b-v) w-k_{2} v, \\
D_{v} \frac{d^{2} v}{d x^{2}} & =-k_{1}(b-v) w+k_{2} v .
\end{aligned}
$$

These two equations, with four proper boundary conditions, which are developed in the next section, give a well-posed mathematical problem.

Another approach is to use the relation between (5) and (6) to reduce them to a single second order differential equation with auxiliary conditions. Add (5) and (6) and integrate once to obtain (7), in which $J_{t}$ is the total flux of oxygen, which is of course constant in the steady state:

$$
-J_{t}=D_{w} \frac{d w}{d x}+D_{v} \frac{d v}{d x}
$$

Now integrate (7) to obtain

$$
-J_{i} x+C=D_{w} w(x)+D_{v} v(x)
$$

Solve (8) for $w(x)$, and substitute in (6) to obtain

$$
D_{v} \frac{d^{2} v}{d x^{2}}=-\frac{k_{1}}{D_{w}}(b-v)\left(C-J_{t} x-D_{t} v\right)+k_{2} v \text {. }
$$

The corresponding equation in $w$ is obtained by substituting for $v$ in (5). Evaluating (8) at $x=0$ and $x=L$ gives auxiliary conditions

$$
\begin{aligned}
D_{w} w(0)+D_{v} v(0) & =C, \\
D_{w} w(L)+D_{v} v(L) & =-J_{t} L+C .
\end{aligned}
$$

Note that $J_{t}$ and $C$ are not known. Of the boundary values $w(0)$ and $w(L)$ are known, but $v(0)$ and $v(L)$ are not known; the boundary conditions on $v$ are $d v / d x=0$ at $x=0, L$. Now, instead of the two second order differential equations (5) and (6) with four boundary conditions, we have one second order differential equation (9) with the two boundary conditions on $v$ and the coupled auxiliary equations (10). This formulation of the problem or the corresponding one in $w$ has been used as the starting point for much of 
the work using singular perturbation methods, and we shall return to it in that context.

\section{BOUNDARY CONDITIONS}

To solve two simultaneous second order equations four conditions are needed. These it turns out are split between the two sides of the membrane, so this is a two point boundary value problem.

Two conditions follow immediately from the inherent physics of the problem. The protein cannot cross the boundary between the aqueous phase in the membrane and the gas phases in chambers 1 and 2 of Figure 1. Thus the boundaries are reflecting boundaries for $v$, and two of the boundary conditions are given by

$$
\left.\frac{d v}{d x}\right|_{0}=\left.\frac{d v}{d x}\right|_{L}=0 .
$$

The other two boundary conditions involve the oxygen, which can cross the boundary between the aqueous and gaseous phases. The actual conditions depend on how the partial pressures are set in chambers 1 and 2 and whether or not there is any resistance to movement of oxygen across the interface.

(i) Let $P_{0}$ and $P_{L}$ be the partial pressures of oxygen in chambers 1 and 2 respectively; these are measured in the experiments. If there is no resistance to oxygen movement across the interface, then the dissolved oxygen at the surfaces will be in equilibrium with the gas phases. Therefore, if $\alpha_{s}$ is the solubility in the aqueous phase, the following equations give the other two boundary conditions:

$$
w(0)=\alpha_{s} P_{0}, \quad w(L)=\alpha_{s} P_{L} .
$$

(ii) If there is any resistance to flow of oxygen across the air-liquid interface because of some boundary layer effect, one obtains a different pair of boundary conditions in place of the equations (12).

Let $G$ be the conductance of the boundary layer and $J_{t}$ be the total oxygen flux in the steady state. Then the following equations give the flux across the boundaries:

$$
J_{\imath}=G\left[P_{0}-P(0)\right]=G\left[P(L)-P_{L}\right]
$$

Here $P(0)$ and $P(L)$ are the partial pressures of oxygen within the membrane at $x=0$ and $x=L$ respectively. But from Equations (7) and (11) we also have

$$
J_{t}=-\left.D_{w} \frac{d w}{d x}\right|_{0}=-\left.D_{w} \frac{d w}{d x}\right|_{L}
$$


Substituting the rclations (14) into (13) with $w(0)=\alpha_{s} P(0)$ and $w(L)=$ $\alpha_{s} P(L)$, one obtains the conditions (15) in place of (12):

$$
\begin{gathered}
\frac{w(0)}{\alpha_{s}}-\left.\frac{D w}{G} \frac{d w}{d x}\right|_{0}=P_{0} \\
w(L)+D w d w \mid=P_{L} \\
\alpha_{s}+\left.G d x\right|_{L}
\end{gathered}
$$

\section{PARAMETER VALUES}

To illustrate the orders of magnitudes of the parameters, Table 1 gives values used by Jacquez et al. [14].

\section{NORMALIZED EQUATIONS}

To normalize Equations (5) and (6) and the boundary conditions, transform the variables as shown:

$$
\begin{aligned}
W & =w / w_{0} \quad\left(w_{0}=\alpha_{s} P_{0}\right), \\
V & =v / b, \\
y & =x / L .
\end{aligned}
$$

Thus $0 \leqslant y \leqslant 1,0 \leqslant W \leqslant 1,0 \leqslant V \leqslant 1$. Substituting in (5) and (6) gives us

$$
\begin{gathered}
\frac{d^{2} W}{d y^{2}}=\alpha \beta \gamma(1-V) W-\alpha \beta V, \\
\frac{d^{2} V}{d y^{2}}=-\alpha \gamma(1-V) W+\alpha V .
\end{gathered}
$$

\begin{tabular}{|c|c|c|c|c|}
\hline & & \multicolumn{2}{|c|}{ Human hemoglobin } & \multirow{2}{*}{$\frac{\text { Horse myoglobin }}{15 \%}$} \\
\hline & & $15 \%$ & $34 \%$ & \\
\hline$b$ & $\left(\right.$ moles $\left./ \mathrm{cm}^{3}\right)$ & $0.9375 \times 10^{-5}$ & $2.125 \times 10^{-5}$ & $7.2 \times 10^{-6}$ \\
\hline$D_{u}$ & $\left(\mathrm{~cm}^{2} / \mathrm{sec}\right)$ & $3.6 \times 10^{-7}$ & $6.8 \times 10^{-8}$ & $8.6 \times 10^{-7}$ \\
\hline$D_{w}$ & $\left(\mathrm{~cm}^{2} / \mathrm{sec}\right)$ & $1.4 \times 10^{-5}$ & $7.0 \times 10^{-6}$ & $1.5 \times 10^{-5}$ \\
\hline$k_{1}$ & $\left(\mathrm{~cm}^{3} /\right.$ mole sec $)$ & $3.0 \times 10^{9}$ & $3.0 \times 10^{9}$ & $14.0 \times 10^{9}$ \\
\hline$k_{2}$ & $\left(\sec ^{-1}\right)$ & 40 & 40 & 11 \\
\hline$\alpha_{s}$ & (mole/ $\mathrm{cm}^{3}$ Torr) & $1.8 \times 10^{-9}$ & $1.8 \times 10^{-9}$ & $1.5 \times 10^{-9}$ \\
\hline
\end{tabular}

TABLE 1

Values for Parameters of Hemoglobin and Myoglobin at $20^{\circ} \mathrm{C}$ 
The dimensionless parameters are

$$
\begin{aligned}
& \alpha=k_{2} L^{2} / D_{v}, \\
& \beta=D_{v} b / D_{w} w_{u}^{\prime}, \\
& \gamma=k_{1} w_{0} / k_{2} .
\end{aligned}
$$

Note that $\alpha$ is the ratio of the backward rate constant to a rate constant characteristic for diffusion across a membrane of thickness $L, \beta$ is a ratio of maximum possible diffusion rates, and $\gamma$ is the ratio of forward to backward rate constants at the left side of the membrane. Yung and Probstein [15] used the equation in $u$ corresponding to Equation (10) and used $\gamma, 1 / \alpha$, and $\delta=1 / \alpha \beta \gamma=D_{w} / k_{1} L^{2} b$ as dimensionless parameters. Both $\alpha$ and $1 / \delta$ are ratios of reaction rate constants to rate constants characteristic for diffusion across the membrane, i.e. Damköhler numbers of the second kind.

Table 2 gives values for the dimensionless parameters for the values of the physical parameters given in Table 1 . For $L$ in the range $1-100 \mu \mathrm{m}$ the values of $\alpha$ vary from fairly small values at $L=1 \mu \mathrm{m}$ to very large values. It is obvious that for $L=100 \mu \mathrm{m}$ and even for $10 \mu \mathrm{m}$ Equations (17) and (18) should be treatable by singular perturbation methods. It is equally clear that this cannot be true for $L$ near $1 \mu \mathrm{m}$.

In normalized form the boundary conditions (11) are given by

$$
\left.\frac{d V}{d y}\right|_{0}=\left.\frac{d V}{d y}\right|_{1}=0 .
$$

The boundary conditions (12) become

$$
\begin{aligned}
& W(0)=1 \\
& W(1)=P_{L} / P_{0}
\end{aligned}
$$

TABLE 2

Values for Dimensionless Parameters at $20^{\circ} \mathrm{C}$

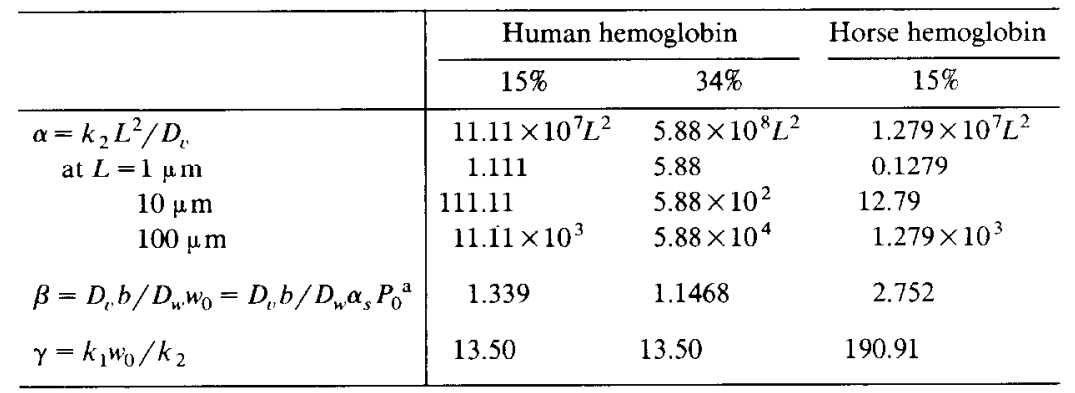

${ }^{\mathrm{a}}$ For $P_{0}=100$. 
and the equations (15) become

$$
\begin{aligned}
& W(0)-\left.\frac{\alpha_{s} D w}{G L} \frac{d W}{d y}\right|_{0}=1, \\
& W(1)+\left.\frac{\alpha_{s} D w}{G L} \frac{d W}{d y}\right|_{1}=\frac{P_{L}}{P_{0}} .
\end{aligned}
$$

For the experimental setup and conventions usually used, $P_{L}<P_{0}$.

\section{THE STEADY STATE EQUATIONS FOR HEMOGLOBIN}

Although we concentrate on myoglobin and its function in muscle, it is worth pointing out the complications met with in dealing with hemoglobin. Hemoglobin has four binding sites for oxygen, so there are really five forms of hemoglobin with four consecutive reactions for adding oxygen, as illustrated by

$$
\begin{gathered}
\mathrm{Hb}+\mathrm{O}_{2} \underset{k_{b}^{1}}{\stackrel{k_{f}^{1}}{\rightleftharpoons}} \mathrm{HbO}_{2}, \\
\mathrm{HbO}_{2}+\mathrm{O}_{2} \underset{k_{b}^{2}}{\stackrel{k_{f}^{2}}{\rightleftharpoons}} \mathrm{Hb}\left(\mathrm{O}_{2}\right)_{2}, \\
\mathrm{Hb}\left(\mathrm{O}_{2}\right)_{2}+\mathrm{O}_{2} \underset{k_{b}^{3}}{\stackrel{k_{f}^{3}}{\rightleftharpoons}} \mathrm{Hb}\left(\mathrm{O}_{2}\right)_{3}, \\
\mathrm{Hb}\left(\mathrm{O}_{2}\right)_{3}+\mathrm{O}_{2} \underset{k_{b}^{4}}{\stackrel{k_{f}^{4}}{\rightleftharpoons}} \mathrm{Hb}\left(\mathrm{O}_{2}\right)_{4} .
\end{gathered}
$$

The rate constants are the constants for hemoglobin as a tetramer. It is convenient to define rate constants on the basis of the individual sites at any stage of the reaction by

$$
\begin{aligned}
k_{f}^{i} & =(4-i+1) k_{1}^{i}, \\
k_{b}^{i} & =i k_{2}^{i},
\end{aligned}
$$

in which $k_{1}^{i}$ and $k_{2}^{i}$ are the intrinsic rate constants. If the different binding sites are completely independent of one another in their reactions with oxygen, then $k_{1}^{1}=k_{1}^{2}=k_{1}^{3}=k_{1}^{4}$ and $k_{2}^{1}=k_{2}^{2}=k_{2}^{3}=k_{2}^{4}$. For hemoglobin the sites do interact, so the intrinsic rate constants differ, i.e. depend on the occupancy of the sites; these effects are referred to as cooperative effects in the biochemical literature.

Let $u_{0}, u_{1}, \ldots, u_{4}$ be the five forms of hemoglobin in ascending order of oxygenation. Equations (25)-(27) are the equations for the different com- 
plexes corresponding to the steady states of equations (3) and (4):

$$
\begin{aligned}
& D_{v} \frac{d^{2} u_{0}}{d x^{2}}=k_{f}^{1} u_{0} w-k_{b}^{1} u_{1} \\
& D_{v} \frac{d^{2} u_{i}}{d x^{2}}=-k_{f}^{i} u_{i-1} w+k_{b}^{i} u_{i}+k_{f}^{i+1} u_{i} w-k_{b}^{i+1} u_{i+1}, \quad i=1,2,3 \\
& D_{v} \frac{d^{2} u_{4}}{d x^{2}}=-k_{f}^{4} u_{3} w+k_{b}^{4} u_{4}
\end{aligned}
$$

It is possible to rewrite these, with the equation for oxygen, as two equations that are formally similar to the steady state forms of Equations (3) and (4). However, the rate coefficients for this bimolecular reaction formulation are no longer constants. I follow the development of Gonzalez-Fernandez and Atta [16]. Multiply each of Equations (25)-(27) by the corresponding value of $i$, in order, and sum and replace the rate constants by (24). This gives

$$
D_{v} \sum_{i=1}^{4} i \frac{d^{2} u_{i}}{d x^{2}}=-w \sum_{i=0}^{3}(4-i) k_{1}^{i+1} u_{i}+\sum_{i=1}^{4} i k_{2}^{i} u_{i}
$$

Note that the concentrations of unoccupied sites $(u)$ and occupied sites $(v)$ are given by

$$
\begin{aligned}
& u=\sum_{i=0}^{3}(4-i) u_{i}, \\
& v=\sum_{i=1}^{4} i u_{i} .
\end{aligned}
$$

Now define rate coefficients by

$$
\begin{aligned}
& k_{1}^{\prime}=\frac{\sum_{i=0}^{3} k_{1}^{i+1}(4-i) u_{i}}{\sum_{i=0}^{3}(4-i) u_{i}}, \\
& k_{2}^{\prime}=\frac{\sum_{i=1}^{4} i k_{2}^{i} u_{i}}{\sum_{i=1}^{4} i u_{i}}
\end{aligned}
$$

Note that if the forward intrinsic rate constants are all equal, $k_{1}^{\prime}$ is a constant 
equal to the forward intrinsic rate constant, and the same is true, mutatis mutandis, for $k_{2}^{\prime}$. Otherwise the rate coefficients $k_{1}^{\prime}$ and $k_{2}^{\prime}$ change as the proportions of the $u_{i}$ change. With the above substitutions Equation (28) becomes

$$
D_{v} \frac{d^{2} v}{d x^{2}}=-k_{1}^{\prime} u w+k_{2}^{\prime} v
$$

which is formally the same as (6), and the equation for $w$ reduces to

$$
D_{w} \frac{d^{2} w}{d x^{2}}=k_{1}^{\prime} u w-k_{2}^{\prime} v,
$$

which is formally the same as (5).

In most of the early work and in some of the more recent work $[1,2,14$, 17-25], Equations (33) and (34) have been used for hemoglobin with average values for $k_{1}^{\prime}$ and $k_{2}^{\prime}$. This treats hemoglobin as though its oxygen saturation curve were hyperbolic like that of myoglobin. Gonzalez-Fernandez and Atta [16] use Equations (33) and (34), but take into account the dependence of $k_{1}^{\prime}$ and $k_{2}^{\prime}$ on the fractional saturation of the hemoglobin. For work in which the four step reaction mechanism is explicitly used, see the papers by Meldon et al. [26], Stroeve et al. [27], and Gijsbers and Van Ouwerkerke [28].

\section{APPROACHES TO SOLUTIONS}

In this section we examine the nature of the solutions. Results on global existence, local uniqueness, and continuity are given by Hanna and Garner [29].

1. THE NATURE OF THE SOLUTIONS: QUALITATIVE AND PHYSICALLY BASED ARGUMENTS

Consider Equations (5) and (6) for the boundary conditions given by (12) with $w(0) \gg w(L)$. Integrating Equation (7) across the membrane gives for the total flux the sum of two terms:

$$
\begin{aligned}
& J_{t}=\frac{D_{w}}{L}[w(0)-w(L)]+\frac{D_{v}}{L}[v(0)-v(L)], \\
& J_{t}=\underbrace{\frac{D_{w} w(0)}{L}[1-W(1)]}+\underbrace{\frac{D_{v} b}{L}[V(0)-V(1)]}, \\
& J_{t}=\quad J_{D}+J_{F} .
\end{aligned}
$$

The first term, $J_{D}$, is the same as the diffusive flux of oxygen when no carrier 
is present; the second is the facilitated flux and depends on the carrier. Both terms are positive, so $J_{t} \geqslant J_{D}$. We define the facilitation by

$$
F=\frac{J_{F}}{J_{D}}=\frac{D_{v} b[V(0)-V(1)]}{D_{w} w(0)[1-W(1)]} .
$$

If $W(1)=0$, an upper bound for $F$ is obtained by using the upper bound on $V(0)-V(1)$ obtained by setting $V(1)=0$ and $V(0)$ equal to the equilibrium value for $W(0)=1$, which is $\gamma /(1+\gamma)=k_{1} w_{0} /\left(k_{2}+k_{1} w_{0}\right)$. Thus (37) gives the upper bound for $F$ :

$$
\sup F=\frac{D_{v} b}{D_{w} w_{0}}\left[\frac{k_{1} w_{0}}{k_{2}+k_{2} w_{0}}\right]
$$

The actual value of $F$ is usually considerably less.

From Equations (4) and (5) and $u+v=b$, the profiles in $u$ and $v$ must have the shapes shown in Figure 4(a). There must be a diffusive flux of $v$ to the right and of $u$ to the left. Since $v$ starts with zero slope at the left side and must eventually decrease and approach the right boundary with zero slope, there must be a point in between where the second derivative is zero. Therefore $u$ and $w$ also have zero second derivatives at the same point; all have a point of inflection at the same distance into the membrane. For $w$, the profile would be a straight line if there were no carrier, as indicated by the dashed line in $4(\mathrm{~b})$. If carrier is present $(b>0)$, the total flux is greater, but at the boundary all of the flux is carried by $w\left(d v /\left.d x\right|_{0}=0\right)$, so $w$ must start with initial slope more negative than when $b=0$. As $w$ diffuses to the right from the left boundary, some of it combines with carrier, so $w$ must decrease more rapidly than in the absence of carrier. From the boundary conditions $w$ must have the same slope at the right boundary as at the left. Therefore the derivative must increase in value to the inflection point, $w$ crossing the dashed line en route, and the derivative must then decrease to the final slope at the right boundary.

Referring to Figure 4(a) and (b), to the left of the inflection point $d^{2} w / d x^{2}$ is positive and $d^{2} v / d x^{2}$ is negative, and these switch signs to the right of the inflection point. Thus to the left of the inflection point $v$ is below the equilibrium value for any value of $w$. Conversely, to the right of the inflection point $v$ is above the equilibrium value. Put another way, to the left of the inflection point the reaction tends to load; to the right, unload.

\section{NUMERICAL INTEGRATION}

The method used by Kutchai et al. [18] and Jacquez et al. [14] is what Bellman and Kalaba [30] have called the method of quasilinearization. Since higher order differential equations can be written as simultaneous first order 


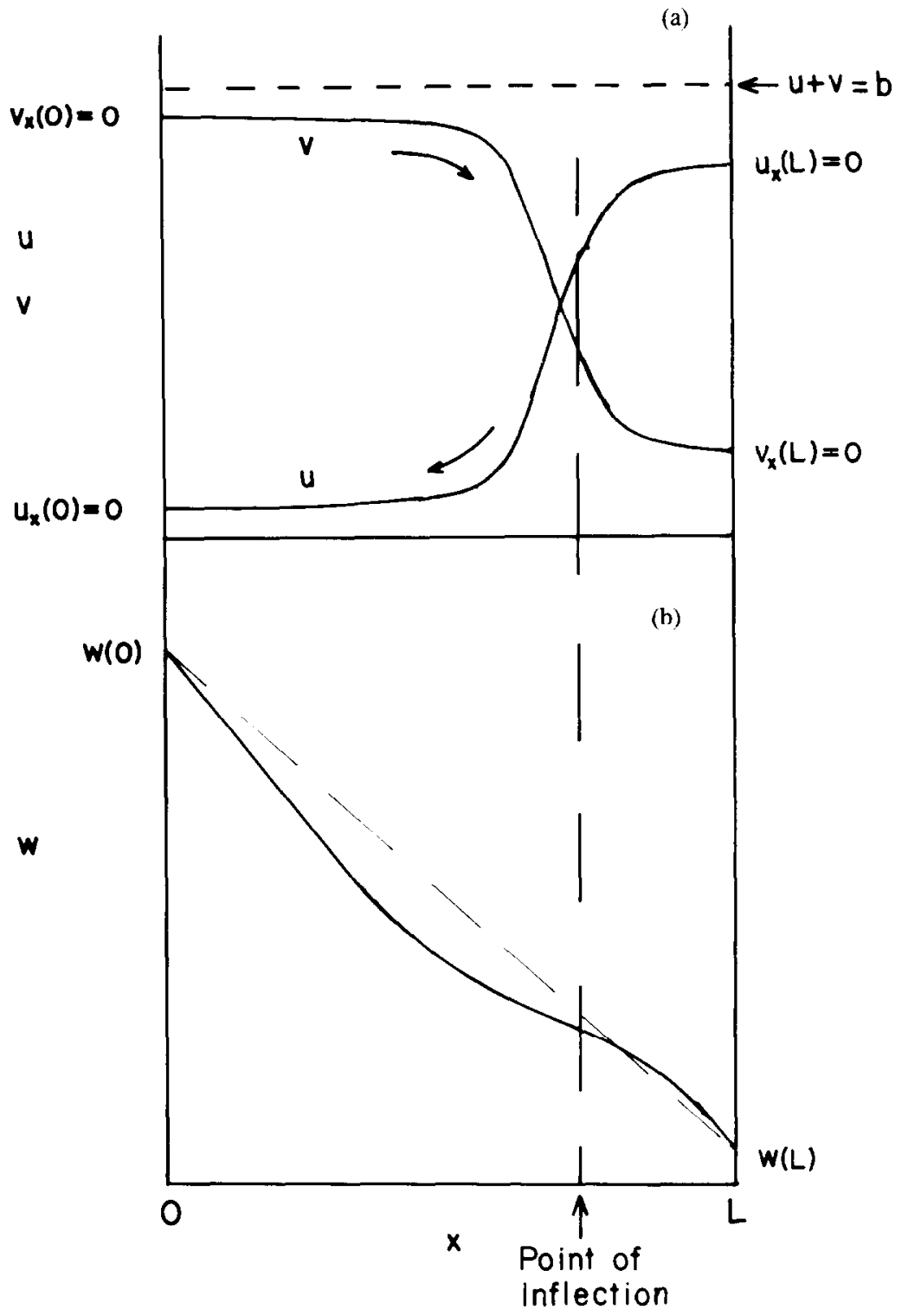

FIG. 4. Diagram of qualitative nature of solutions: (a) profiles of $u$ and $v$, (b) profile of $w$. 
differential equations, let us illustrate the major steps with a boundary value problem in two first order nonlinear differential equations. Suppose the equations are

$$
\begin{aligned}
& \frac{d y_{1}}{d x}=f_{1}\left(x, y_{1}, y_{2}\right), \\
& \frac{d y_{2}}{d x}=f_{2}\left(x, y_{1}, y_{2}\right)
\end{aligned}
$$

with boundary conditions

$$
y_{1}(0)=a, \quad y_{2}(1)=b .
$$

Guess solutions $z_{1}(x)$ and $z_{2}(x)$ that match the boundary conditions, and expand the right sides of (38) and (39) in Taylor's series about $z_{1}(x)$ and $z_{2}(x)$, dropping terms after the first derivatives:

$$
\begin{aligned}
& \frac{d y_{1}}{d x}=f_{1}\left(x, z_{1}, z_{2}\right)+\left.\frac{\partial f_{1}}{\partial y_{1}}\right|_{z_{1}}\left(y_{1}-z_{1}\right)+\left.\frac{\partial f_{1}}{\partial y_{2}}\right|_{z_{2}}\left(y_{2}-z_{2}\right) \\
& \frac{d y_{2}}{d x}=f_{2}\left(x, z_{1}, z_{2}\right)+\left.\frac{\partial f_{2}}{\partial y_{1}}\right|_{z_{1}}\left(y_{1}-z_{1}\right)+\left.\frac{\partial f_{2}}{\partial y_{2}}\right|_{z_{2}}\left(y_{2}-z_{2}\right)
\end{aligned}
$$

Since $z_{1}$ and $z_{2}$ are known functions of $x,(41)$ and (42) are linear differential equations with variable coefficients. Write (41) and (42) in terms of the deviations $e_{1}=y_{1}-z_{1}$ and $e_{2}=y_{2}-z_{2}$, giving

$$
\begin{aligned}
& \frac{d e_{1}}{d x}=f_{1}\left(x, z_{1}, z_{2}\right)-\frac{d z_{1}}{d x}+\left.\frac{\partial f_{1}}{\partial y_{1}}\right|_{z_{1}} e_{1}+\left.\frac{\partial f_{1}}{\partial y_{2}}\right|_{z_{2}} e_{2}, \\
& \frac{d e_{2}}{d x}=f_{2}\left(x, z_{1}, z_{2}\right)-\frac{d z_{2}}{d x}+\left.\frac{\partial f_{2}}{\partial y_{1}}\right|_{z_{1}} e_{1}+\left.\frac{\partial f_{2}}{\partial y_{2}}\right|_{z_{2}} e_{2}
\end{aligned}
$$

with boundary conditions

$$
e_{1}(0)=0, \quad e_{2}(1)=0 .
$$

Divide $[0,1]$ into $n$ equal intervals, and rewrite (43) and (44) in terms of finite differences at the midpoint of each interval. With (45) this gives a set of simultaneous linear algebraic equations in $e_{1}$ and $e_{2}$ at each of the mesh points. Solve, correct $z_{1}$ and $z_{2}$, and iterate.

There is no guarantee of convergence, but if the process converges it converges quadratically. Since convergence depends on having good initial guesses for $z_{1}$ and $z_{2}$, and it may be difficult to make such guesses for some problems, what is one to do? 
One way around this difficulty is to use "continuation in parameter space." Generally the solutions will be continuous functions in some or all of the parameters. Furthermore one can usually find special values for one or more parameters for which the solutions are known or for which good approximations can be found. The strategy then is to solve the problem for such a value of the particular parameter and then change the value of the parameter, using the solutions for the previous value as the initial guesses for $z_{1}$ and $z_{2}$ for the next value. In this way one can often find solutions for a range of values of the parameter.

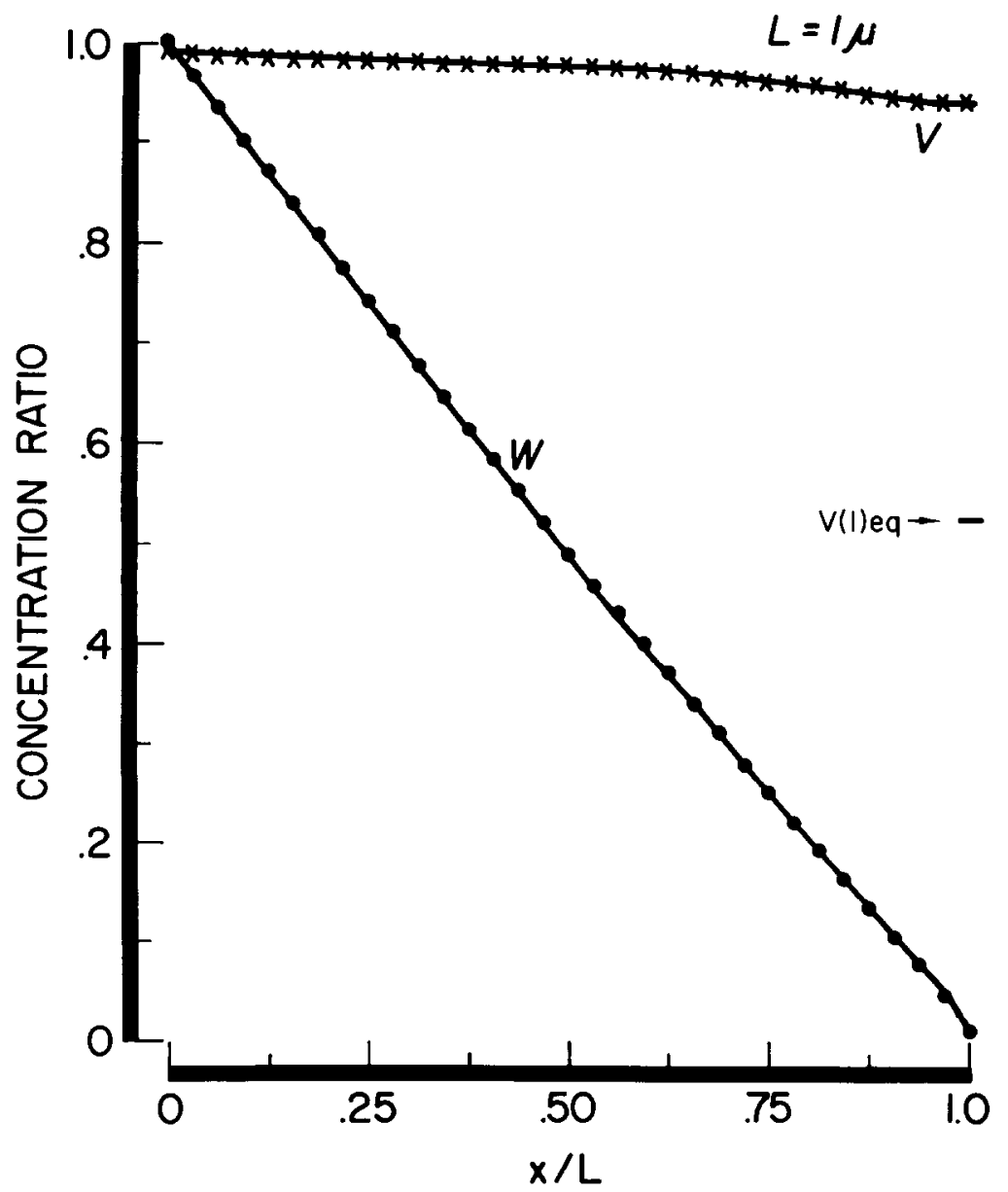

Fig. 5. Solution for $1 \mu \mathrm{m}$ membrane. 
In the work of Kutchai et al. [18] a series of initial guesses for $25 \mu \mathrm{m}$ and $100 \mu \mathrm{m}$ membranes failed to give convergence. For $1 \mu \mathrm{m}$ membranes it was found that, using a straight line for $W$ to connect its boundary values and taking $V$ in equilibrium with $W$ for initial guesses, the process converged rapidly. These solutions worked as initial guesses for $2 \mu \mathrm{m}$ membranes. In this way solutions for $1,2,5,10,25,50,100,300$, and $1000 \mu \mathrm{m}$ membranes were generated in succession. Figures 5-8 show some profiles for $W$ and $V$ for membranes of different thickness with the parameters for hemoglobin.

Gonzalez-Fernandez and Atta [16] use a method that involves a piecewise linearization to generate numerical solutions. Both methods, [16] and [18], give essentially the same results.

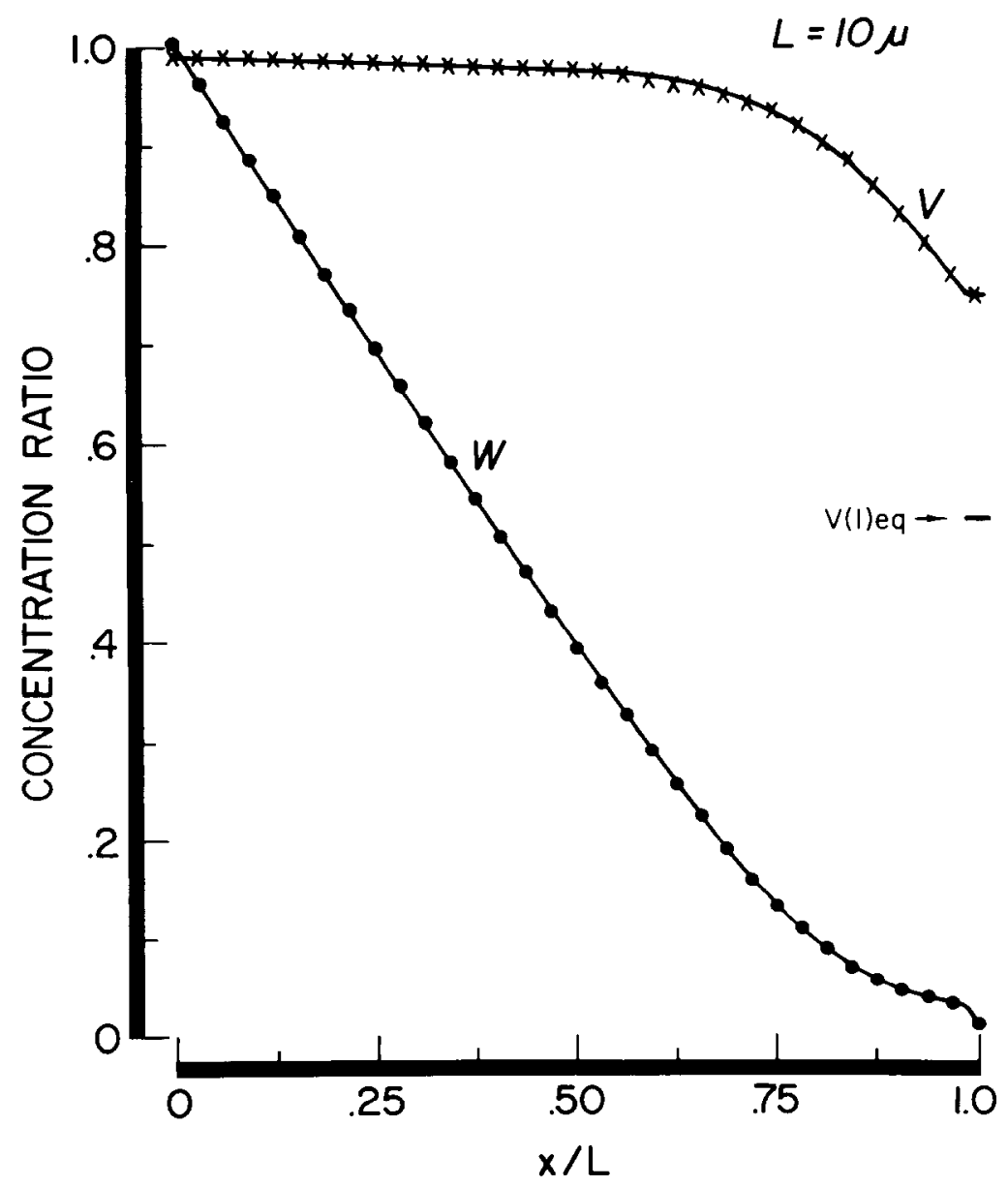

FIG. 6. Solution for $10 \mu \mathrm{m}$ membrane. 


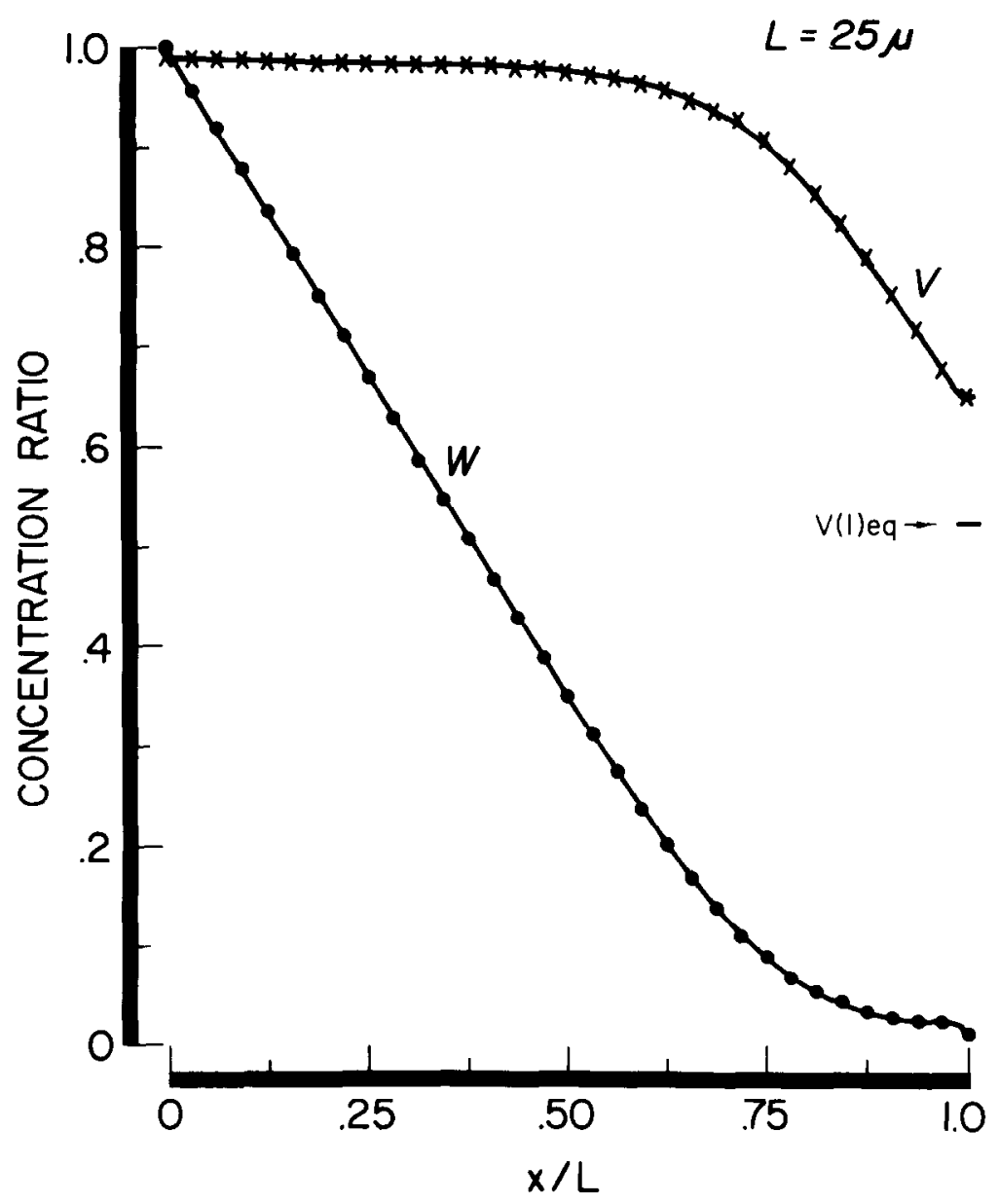

Fig. 7. Solution for $25 \mu \mathrm{m}$ membrane.

As will be seen later, many of the approximation methods assume chemical equilibrium or a quasiequilibrium in the membrane. The numerical methods used by Gonzalez-Fernandez and Atta [16] and others $[14,18]$ do not make such assumptions.

3. OTHER FINITE DIFFERENCE MODELS: THE COMPARTMENTAL APPROACH

To attack the problem numerically, divide the interval $[0,1]$ into $n$ intervals and replace the derivatives by finite differences to obtain a set of difference equations on the grid points. This gives a set of simultaneous 


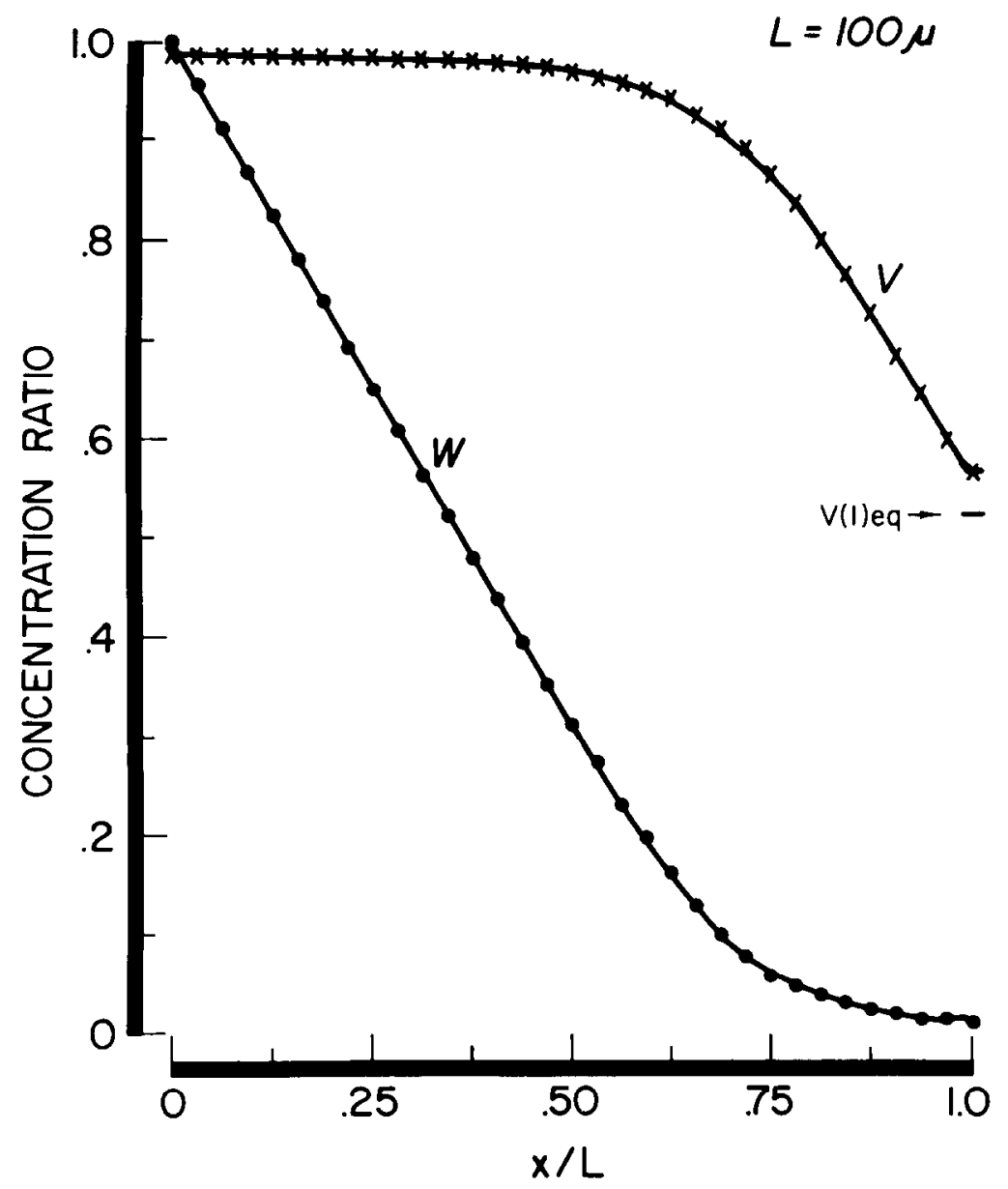

FIG. 8. Solution for $100 \mu \mathrm{m}$ membrane.

nonlinear algebraic equations which can be very difficult to solve. To get around this one must use iterative linearizations of the type used in quasilinearization.

The previous methods involved a discretization of a continuum mathematical formulation of the problem. Another method is to introduce the discretization directly at the physical level of problem formulation by replacing the membrane with a series of $n$ well-stirred small partitions as in Figure 9. This gives $n$ compartments in $w$ and $n$ in $v$ which are linked. Mass 


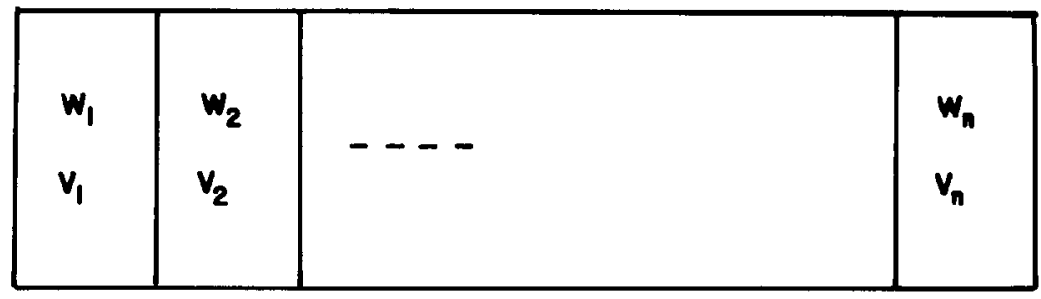

Fig. 9. Partition for deriving compartmental model.

balance equations are then written for the 1 st, the $i$ th, and the $n$th partition:

$$
\begin{aligned}
0= & -\frac{D_{w}\left(w_{0}-w_{1}\right)}{L / 2 n}+\frac{D_{w}\left(w_{1}-w_{2}\right)}{L / n} \\
& -k_{1}\left(b-v_{1}\right) w_{1} \frac{L}{n}+k_{2} \frac{L}{n} v_{1}, \\
0= & \frac{D_{w}\left(w_{i-1}-2 w_{i}+w_{i+1}\right)}{(L / n)^{2}}-k_{1}\left(b-v_{i}\right) w_{i}+k_{2} v_{i}, \\
0= & -\frac{D w\left(w_{n-1}-w_{n}\right)}{L / n}+\frac{D_{w}\left(w_{n}-w_{L}\right)}{L / 2 n} \\
& -k_{1}\left(b-v_{n}\right) w_{n} \frac{L}{n}+k_{2} \frac{L}{n} v_{n} .
\end{aligned}
$$

These finite difference approximations give $n$ nonlinear algebraic equations in the $w$ 's. Another set of $n$ equations can be written for the $v$ 's. Note that the boundary conditions are incorporated in the equations. Since these are nonlinear algebraic equations, an iterative linearization can be used to find the solutions. It turns out then that the formulation looks very much like the method of quasilinearization, an iterative linearization of a finite difference approximation. With this approach it is easy to explicitly include boundary layers at each surface of the membrane.

4. ANALYTICAL APPROXIMATIONS

Rewrite equations (17) and (18) in the form

$$
\begin{aligned}
& \epsilon_{1} \frac{d^{2} W}{d y^{2}}=(1-V) W-\mu V, \\
& \epsilon_{2} \frac{d^{2} V}{d y^{2}}=-(1-V) W+\mu V,
\end{aligned}
$$


TABLE 3

\begin{tabular}{ccc}
\multicolumn{3}{c}{ Parameter Values for Hemoglobin and Myoglobin $\left(20^{\circ} \mathrm{C}\right)$} \\
\hline Parameter & $15 \% \mathrm{Mb}$ & $34 \% \mathrm{Hb}$ \\
\hline$\epsilon_{1}=1 / \alpha \beta \gamma$ & $1.5 \times 10^{-10} / L^{2}$ & $1 \times 10^{-10} / L^{2}$ \\
$\epsilon_{2}=1 / \alpha \gamma$ & $4 \times 10^{-10} / L^{2}$ & $1.25 \times 10^{-10} / L^{2}$ \\
$\mu=1 / \gamma$ & 0.005 & 0.075 \\
\hline
\end{tabular}

where

$$
\epsilon_{1}=\frac{1}{\alpha \beta \gamma}, \quad \epsilon_{2}=\frac{1}{\alpha \gamma}, \quad \mu=\frac{1}{\gamma}
$$

Table 3 gives rough values for $\epsilon_{1}, \epsilon_{2}$, and $\mu$ for $34 \%$ hemoglobin and $15 \%$ horsc myoglobin. Obviously $\epsilon_{1}$ and $\epsilon_{2}$ are extremely small for membranes thicker than about $10 \mu \mathrm{m}$, so a singular perturbation approach can be used, but this is certainly not true for thin membranes of the thickness of a red blood cell. For application to facilitated diffusion in the red blood cell ( $L=2$ $\mu \mathrm{m}$ ), the second derivative term is not negligible in comparison with the reaction terms.

More generally, $\epsilon_{1}$ and $\epsilon_{2}$ are Damköhler numbers of the second kind, ratios of a diffusion rate constant to a reaction rate constant. Thus as the diffusion becomes fast in relation to the chemical reaction rate, as in the thin membrane limit, the second derivative term becomes dominant and the solution approaches that of the simple diffusion problem without chemical reaction. Therefore for thin films a regular perturbation expansion should be applicable. Smith et al. [31] and Suchdeo and Schultz [32] provide this. Smith et al. [31] have shown that more than second order terms are required in the regular perturbation expansion to fit numerical results on $1 \mu \mathrm{m}$ membranes.

At the other extreme, the reaction rate becomes more and more important as the membrane thickness increases, the second derivative term eventually becomes negligible, and the solution approaches one in which the reaction is at equilibrium at all points in the membrane. For thick membranes a singular perturbation expansion has to be used; Schultz et al. [3] discuss criteria for near-diffusion and near-equilibrium conditions. The singular perturbation approach should be applicable to membranes $10 \mu \mathrm{m}$ or more in thickness. Since most of the experimental studies with artificial membranes have used membranes of $100-500 \mu \mathrm{m}$ in thickness, they should fall well in the range of the singular perturbation method [31]. Singular perturbation approaches are given by Murray [20], Mitchell and Murray [21], Kreuzer and Hoofd [17], Smith et al. [31], Schultz et al. [3], Goddard et al. [4], and Rubinow and Dembo [23]. 
To illustrate the singular perturbation approach briefly, (51) gives the equation in $w$ equivalent to Equation (9), in dimensionless form:

$$
\begin{aligned}
& \frac{1}{\alpha \beta \gamma} \frac{d^{2} W}{d y^{2}}=\left(1-c y-d+\frac{W}{\beta}\right) W-\frac{c y+d-W / \beta}{\gamma}, \\
& c=-\frac{J_{t} L}{b D_{v}}, \quad d=\frac{W(0)}{\beta}+V(0), \quad \epsilon=1 / \alpha \beta \gamma
\end{aligned}
$$

Note that $J_{t}$ and $V(0)$ are unknown and should come out of the solution of the equations. Integration of (51) would give two more constants of integration, giving a total of four to be determined from the four boundary conditions. The solution in the interior of the membrane is written as an expansion in powers of $\epsilon^{1 / 2}$. The zero order term of that expansion is obtained from Equation (51) by setting $€ d^{2} W / d y^{2}=0$ and so corresponds to reaction equilibrium.

In many of the early studies on hemoglobin the equilibrium assumption was used throughout the membrane to approximate the solutions; see Kreuzer and Hoofd [17] for references. However, the equilibrium assumption cannot hold out to the boundaries, because the boundary conditions $d V / d y=0$ are then not satisfied. Actually, the equilibrium assumption gives a good approximation at the left boundary even for membranes as thin as $2 \mu \mathrm{m}[14$, 18]; the problems arise at the right boundary. In Figures 5-8, the equilibrium value of $V(1)$ for the given $W(1)$ is shown as well as the true value of $V(1)$. Note that $V(1)$ approaches the equilibrium value as the membrane thickness increases. For more data on this see References [14] and [18].

Murray [20] specified $W(0), W(1)$ and $V(0), V(1)$ for boundary conditions to obtain the zero order solution, but pointed out that $V(0)$ and $V(1)$ cannot really be assigned arbitrarily, and Mitchell and Murray [21] affirmed that the proper boundary conditions on $V$ are $d V / d y=0$. This is a point worth emphasizing because consideration of experimental results has in fact confused the situation here. The experimentalist can measure $P_{0}, P_{L}$, and the total flux $J_{t}$, all with some experimental error. The assumption of equilibration of gas at the membrane surface gives $w(0)$ and $w(L)$ from $P_{0}$ and $P_{L}$. The assumption of reaction equilibrium at the left boundary gives a good approximation to $v(0)$ and hence $C$ from the first equation of $(10)$, and using the measured value of $J_{t}$ then gives $v(L)$ from the second equation of (10). Thus one might be tempted to use these values for boundary conditions. However, the $V(0)$ and $V(1)$ so obtained are influenced by the experimental errors. More importantly, these boundary conditions are not consistent with the inherent physics, the structure of the problem. The proper boundary conditions on $V$ are $d V / d y=0$ at the boundaries; these, with Equations (17) and (18) and the boundary conditions $W(0)$ and $W(1)$, form a well-posed 
problem, which has one solution for $V(0)$ and for $V(1)$. Thus one cannot arbitrarily assign $V(0)$ and $V(1)$ and satisfy the problem with boundary conditions $d V / d y=0$.

In the thin boundary layers $W$ can change rapidly, so that $c d^{2} W / d y^{2}$ is not necessarily negligible. To find solutions in the thin boundary layers stretching transformations are introduced, $z=y / \varphi(\epsilon)$ at the left boundary and $\eta=(1-y) / \varphi(\epsilon)$ at the right boundary. The equation at the left boundary becomes

$$
\frac{\epsilon}{\varphi(\epsilon)^{2}} \frac{d^{2} W}{d z^{2}}=\left(\begin{array}{ll}
\left.1-c z \varphi(\epsilon)-d+\begin{array}{l}
W \\
\beta
\end{array}\right) W \cdots & 1 \\
\gamma
\end{array}\left(\begin{array}{ll}
c z \varphi(\epsilon)+d & W \\
\beta
\end{array}\right) .\right.
$$

Choosing $\varphi(\epsilon)=\epsilon^{1 / 2}$ makes the equations in the boundary layers regular second order differential equations and provides the basis for using expansions in $\epsilon^{1 / 2}$. Assuming $V$ is approximately constant in the boundary layers [17] converts (52) into a linear differential equation and gives exponential solutions in the boundary layers.

In the complete singular perturbation method [33] the solution in the interior of the membrane (the outer solution) is obtained in powers of $\epsilon^{1 / 2}$. Then, with the use of stretching transformations, the boundary layer solutions (the inner solutions) are obtained as expansions in $\epsilon^{1 / 2}$, and enough terms are retained to satisfy the boundary conditions and to match the inner solution at the transitions from the boundary layers to the interior. Rubinow and Dembo [23] give these expansions and show that the zero order term for the outcr solution is adcquate for hemoglobin but that for myoglobin terms in $\epsilon^{1 / 2}$ and in $\epsilon$ have to be kept.

\section{DELIVERY OF OXYGEN TO MUSCLE}

What is the role of myoglobin in oxygen uptake by muscle? From the amount of myoglobin in skeletal muscle and the rate of oxygen consumption one can calculate that the myoglobin could store enough oxygen to last about 8 seconds at maximal oxygen consumption, or about 1 minute at rest. Thus it could scrve as a buffer in sudden changes in activity. However, the major focus in recent years has been on its possible role in facilitating the diffusion of oxygen. Another possibility, on top of a facilitation effect, is that of a valving effect. At physiological $P_{\mathrm{O}_{2}}$ 's the forward reaction rate is much faster than the backward rate, so there is the possibility that uptake of oxygen by myoglobin near capillaries acts like a valve favoring $\mathrm{O}_{2}$ uptake during oscillation of $P_{\mathrm{O}_{2}}$ at the capillary.

Let us examine these possibilities in light of the structural and functional characteristics of skeletal muscle. But first, is there any experimental evidence for the rolc of myoglobin in oxygen uptake? 
1. EXPERIMENTAL APPROACHES TO MYOGLOBIN FUNCTION IN MUSCLE

In 1968 Moll [34] measured diffusion coefficients for myoglobin in homogenates of rat muscle and calculated values of $1.5 \times 10^{-7} \mathrm{~cm}^{2} / \mathrm{sec}$ at $20^{\circ} \mathrm{C}$ and $2.7 \times 10^{-7}$ at $37^{\circ} \mathrm{C}$. He concluded that the contribution of facilitated diffusion of oxygen was small.

A number of studies have been made on intact muscle fibers. Wittenberg and Wittenberg [35] measured oxygen consumption in thin bundles of resting muscle fibers from pigeon breast muscle as a function of the $P_{\mathrm{O}_{2}}$, in vitro. As the $P_{\mathrm{O}_{2}}$ increases, oxygen consumption saturates. At $P_{\mathrm{O}_{2}}$ 's around that for half maximal uptake, inactivation of the myoglobin by reacting it with nitrite, hydroxylamine, or hydroxyethylhydrazine cut oxygen consumption approximately in half, but about the same saturation level of uptake was reached when $P_{\mathrm{O}_{2}}$ was increased. Thus there was a right shift in the curve of oxygen consumption versus $P_{\mathrm{O}_{2}}$. This situation was modeled by Murray [36] and Taylor and Murray [37] as a uniformly distributed consumption in a circular cylinder of myoglobin with constant $P_{\mathrm{O}_{2}}$ at the surface. Subsequently, Cole, Wittenberg, and Caldwell [38] tried a similar experiment with isolated dog heart perfused with a hemoglobin-free fluorocarbon-Ringer lactate. Addition of $8 \mathrm{mM}$ nitrite to the perfusate, to inactivate the myoglobin, had no effect on oxygen consumption or on mechanical performance. More recently Cole [39] has shown that in exercising gastrocnemius-plantaris of the dog, perfusion with a hydrogen-peroxide-containing solution to inactivate myoglobin decreased oxygen consumption to about $65 \%$ of the pretreatment level. An unexplained finding in this study is that contractile tension fell in parallel with oxygen consumption, so one must wonder whether other components of the muscle fiber were damaged by the hydrogen peroxide.

Gayeski and Honig [40] looked at the oxygen saturation of myoglobin in single cells of dog gracilis that had been frozen rapidly and brought to $-110^{\circ} \mathrm{C}$. They found that the myoglobin is highly saturated at just about all sites in resting gracilis muscle and concluded that facilitated diffusion of oxygen on myoglobin could not play a significant role in this muscle at rest.

There are two interesting studies on oxygen transfer into or across thin slices of respiring chicken gizzard muscle, a smooth muscle with a high myoglobin content. Schwarzmann and Grunewald [41] used the rapid freeze method and spectrophotometry to measure the profile of myoglobin saturation in slices of chicken gizzard equilibrated with known pressures of oxygen at the surfaces. From comparison of the profiles with theory they concluded that the mobility of myoglobin in their preparation was limited and facilitated diffusion made only a small contribution to movement. de Koning et al. [42] measured steady state oxygen transfer across the same preparation and used carbon monoxide to block myoglobin. Carbon monoxide would be 
expected to inhibit oxygen consumption as wcll. They concluded that oxygen consumption interferes with the facilitation effect and that the facilitation was less than that expected from theory. Both of these studies have the drawback that they look at oxygen movement across a slice which is many cells thick but compare the results with those expected from a theory in which myoglobin is assumed to be uniformly distributed and free to move across the slice [43]. The myoglobin is restricted to the cells and cannot move freely across the cell boundaries, so one would expect this to decrease the facilitation effect. Gonzalez-Fernandez and Atta [44] have shown that the facilitation decreases as the number of membranes in the diffusion path increases. As the number of protein-impermeable barriers increases, the limit is that of nonmobile binding sites, for which there cannot be any steady state facilitation. The important question is whether there can be any significant facilitation within one cell, between the surface and the mitochondria.

In balance these studies suggest that myoglobin could play a role in oxygen uptake in muscle, but do not provide evidence for any strong facilitation effect in normal resting muscle.

\section{SKELETAL MUSCLE: STRUCTURAL AND FUNCTIONAL CONSIDERATIONS}

(a) Structure. Skeletal muscle cells, also called muscle fibers, are long, approximately cylindrical cells that may have diameters of 10 to $100 \mu \mathrm{m}$. The plasma membrane is a lipid and protein membrane similar to that of other cells, but is usually called the sarcolemma. Each cell has in it many long, parallel cylindrical units of about $1 \mu \mathrm{m}$ diameter, called the myofibrils. Each myofibril is made up of short cylindrical units stacked end to end, called sarcomeres; a diagram is shown in Figure 10. Each sarcomere is made up of two types of thin unit fibers arranged longitudinally along the fiber: actin and myosin. The two types of fibers interdigitate, neither extending the full length of a sarcomere. Actin filaments extend from the $Z$ line in either direction, whereas the myosin fibers lie in the $A$ band. In contraction these

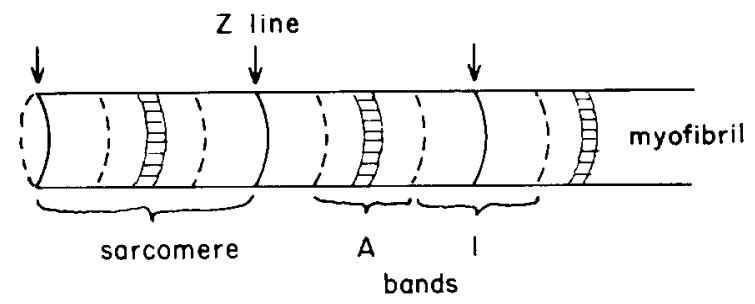

FIG. 10. Diagram of myofibril with sarcomeres. 
two filament types slide past each other, shortening the sarcomcre. In shortening the transverse diameter of the muscle cell increases. For more details on the structural relations between muscle, muscle cell, myofibril, and the actin and myosin filaments sec Bloom and Fawcett [45] and Smith [46].

Surrounding the myofibrils is a system of connected tubules and vesicles called the sarcoplasmic reticulum [47]. The sarcoplasmic reticulum releases $\mathrm{Ca}^{+}$to initiate contraction and takes it up again after contraction. At the $Z$ lines expanded sacs of the sarcoplasmic reticulum come in contact with tubules that are invaginations of the cell membrane: the transverse tubular system. The latter is involved in relaying the depolarization signal in to the sarcoplasmic reticulum.

Oxygen consumption occurs in another set of membrane-bound structures, the mitochondria, which are about $0.1 \mu \mathrm{m}$ in diameter and one to a few micrometers in length. The mitochondria are found between the myofibrils and also just under the sarcolemma. In oxidative metabolism, ATP, the final common chemical unit of energy transfer in cells, is generated in the mitochondria as the final product of a series of chemical reactions which involve use of molecular oxygen, $\mathrm{O}_{2}$. ATP is used in the muscle cell directly at the contractile fibers and also for uptake of calcium by the sarcoplasmic reticulum and for ejection of calcium across the sarcolemma.

(b) The Mitochondria and Oxygen Consumption. There are three types of muscle fibers, which used to be called the red, intermediate, and white fibers $[48,49]$ and now are designated I, IIa, and IIb. Types I and IIa are oxidative fibers, i.e. work oxidatively, whereas the IIb fibers are the fast glycolytic fibers. Type I fibers are the smallest in diameter, have the largest amount of mitochondria, and have a high myoglobin content. These are the fibers involved in repetitive oxidative contraction. Type IIa fibers have less mitochondria and less myoglobin, whereas IIb fibers have few mitochondria and no myoglobin. It is the type I fibers that are of primary interest for us.

Oxygen consumption occurs in the mitochondria, and the three fiber types differ in the disposition, number, and types of mitochondria in them. All fiber types have pairs of mitochondria encircling myofibrils at the I band. Thus these give a fairly regular pattern of distribution throughout the muscle fiber. Intermediate and red fibers have, in addition, columns of mitochondria arranged between myofibrils, the intermyofibrillar mitochondria, and a layer of mitochondria just below the surface, the subsarcolemmal mitochondria. The difference between the two appears to be quantitative: the intermediate fibers have less mitochondria. In cross section, the red fibers have a distinctive arrangement of mitochondria with a heavy subsarcolemmal band and an arrangement of intermyofibrillar mitochondria that gives a banding effect. This is shown diagrammatically in Figure 11. The articles by Gauthier [49] 


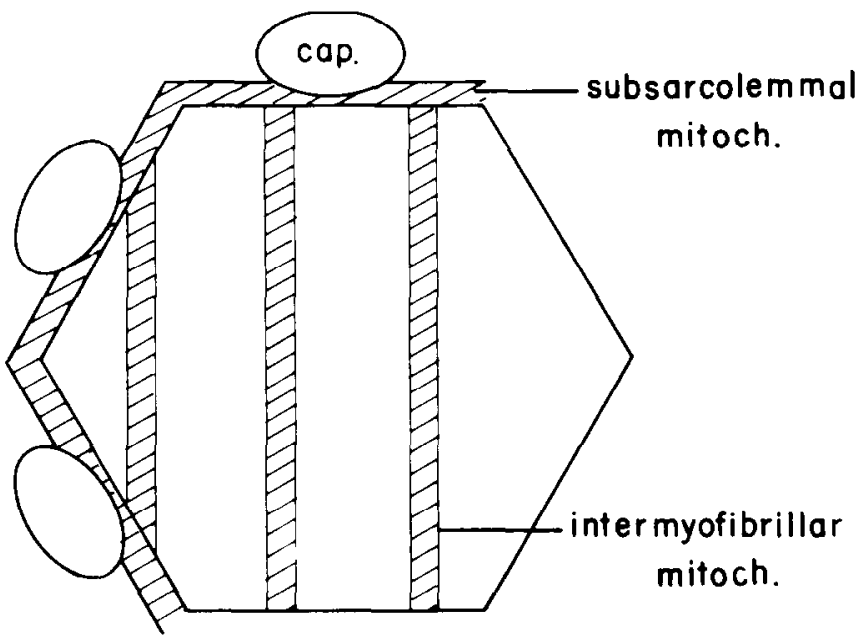

FIG. 11. Diagram of idealized red muscle fiber showing arrangement of capillaries and mitochondria.

and Hoppeler et al. [50] should be consulted for pictures of these arrangements. Furthermore the subsarcolemmal and intermyofibrillar mitochondria differ, the latter having higher enzyme activities and oxygen uptake per milligram of protein [51].

Training appears to have two effects. It is well documented that endurance training increases the mitochondrial content of red muscle $[52,53]$, both intermyofibrillar and subsarcolemmal. There is also evidence that there is an increase in oxygen uptake per milligram of mitochondrial protein, the increase being greater in the subsarcolemmal mitochondria [47].

It has been estimated that the $\mathrm{P}_{\mathrm{O}_{2}}$ at the mitochondria lies between $0.2-2$ Torr [1], but this may not be true for the subsarcolemmal mitochondria. Oxygen consumption by mitochondria shows a saturation effect describable with a Michaelis-Menten type of relation. Estimates of the $K_{m}$ run from $P_{\mathrm{O}_{2}}$ 's of $0.2-0.3$ Torr at $37^{\circ} \mathrm{C}$ [54] to a calculated value of 1 Torr [55]. But for chicken gizzard de Koning et al. [42] give a value of 2.25 Torr. Chance [56] gives values of $0.052-0.085 \mu \mathrm{M}(0.033-0.054$ Torr) for beef heart mitochondria at $25^{\circ} \mathrm{C}$, and Bârzu and Satre [57] give values of $0.14-0.19 \mu \mathrm{M}$ (0.088-0.12 Torr) for rat liver mitochondria and $0.26-0.28 \mu \mathrm{M}(0.16-0.18$ Torr) for beef adrenal cortex mitochondria, both at $26.5^{\circ} \mathrm{C}$.

A significant conclusion from what is known of mitochondrial disposition is that oxygen consumption cannot be considered to be uniformly distributed. In fact the disposition of the mitochondria appears to be such that they 
are close to the sites where ATP is required: the cell membrane (subsarcolemmal) and the actomyosin and sarcoplasmic reticulum (the intermyofibrillar and the mitochondria at the I bands). Whatever the situation with respect to diffusion of oxygen, the mitochondria are disposed so that the ATP they produce will not have to diffuse far.

(c) The Blood Supply. The capillaries in skeletal muscle tend to run parallel with the muscle fibers. However, their number and arrangement differ for the different fiber types. White fibers have few capillaries, which tend to run a fairly straight course with cross connections, giving the appearance of long loops. The red fibers have many cross connections, and the capillaries wander around the fiber's surface, covering a considerable portion of it $[58,59]$. The high oxidative red fibers may have $6-8$ capillaries around a fiber, whereas the low oxidative fibers may have only one or less (see Figure 3 of Romanul [59]). In red fibers the capillaries indent the cell, and just underneath the capillaries the subsarcolemmal sheath of mitochondria is thinned or absent, as is shown diagrammatically in Figure 11 which is a diagrammatic idealization of Figure 6 from Hoppeler et al. [50] and Figure 3 from Romanul [59]. Furthermore there is a continuous flow in the capillaries that are open around red fibers and an intermittent flow to capillaries of white fibers. Not all capillaries are open when a muscle is not working; more and more open as muscular effort increases. Finally it should be remembered that most muscles are mixed, containing all three types of fibers, which are not randomly mixed, so capillary distribution is nonuniform, following the distribution of fiber types. In heart muscle, on the other hand, there is evidence [60] that the capillaries are distributed in an ordered square array.

The partial pressure of oxygen in pulmonary alveoli is about 100 Torr, while that in mixed blood leaving the lungs is about 97 Torr [54]. Arterial blood in peripheral arteries has been reported to have a partial pressure of 95-100 Torr in 20-30 year olds and 87-91 Torr in 50-60 year olds [61]. In exercise arterial $P_{\mathrm{O}_{2}}$ remains unchanged while cardiac output and the difference between arterial and mixed venous blood oxygen increase [62]. Presumably some oxygen can diffuse across the walls of small arteries, so the $P_{\mathrm{O}_{2}}$ of blood entering the capillaries may be lower [63, 64], but even at a partial pressure of 80 Torr the hemoglobin is saturated $95 \%$ with oxygen. At rest the mixed venous blood has a $P_{\mathrm{O}_{2}}$ near 40 Torr, and this falls with exercise. During contraction the flow increases [65], but not as rapidly as the oxygen consumption. At the same time the resistance to flow increases in a unit capillary; the increase in flow is due to opening of more capillaries. In rhythmic contraction flow becomes cyclic, decreasing during the contractile phase and increasing during relaxation. At maximal contraction the oxygen 
saturation of venous blood leaving muscle falls to as low as $28 \%\left(P_{\mathrm{O}_{2}}=17-18\right.$ Torr $)$ in cat soleus and $11 \%\left(P_{\mathrm{O}_{2}}=8-9\right.$ Torr in cat gastrocnemius [55].

\section{PARAMETER VALUES}

In this section I want to gather together values for parameters and present supporting arguments where I think they are needed.

Myoglobin appears to be distributed uniformly in the cytoplasm of red muscle fibers [66, 67]. Wittenberg [1] summarizes data on the myoglobin content of skeletal muscles. For the soleus, which is a good example of a red muscle, we can use $0.45 \times 10^{-3}$ mole $/(\mathrm{kg}$ wet weight $)$. About $\frac{1}{3}$ of the muscle volume is due to mitochondria, and it is highly likely that myoglobin is excluded from mitochondria, giving $0.675 \times 10^{-3}$ mole $/ \mathrm{kg}$ in cytoplasm. Furthermore the myofibrillar proteins myosin and actin constitute up to $18 \%$ of the weight, so if one takes into account the volume occupied by the myofibrils, myoglobin must be at approximately a concentration of $0.8 \times 10^{-3}$ moles $/ \mathrm{kg}$ in the cytoplasm between the myofibrils. We shall use $0.8 \times 10^{-3}$; a range of $(0.5-1) \times 10^{-3}$ probably brackets the actual values.

Myoglobin diffusion has recently been measured by NMR in freshly excised beef heart; it has a diffusion rate intracellularly about one-half that in dilute solution, about the same as in an $18 \%$ solution of bovine serum albumin [68]. The diffusion coefficient of myoglobin in an $18 \%$ solution is $7 \times 10^{-7} \mathrm{~cm}^{2} / \mathrm{sec}$ at $20^{\circ} \mathrm{C}$ [69]. From the Sutherland-Einstein relation, $D=R T / N 6 \pi \eta r$, one obtains

$$
\frac{D_{310}}{D_{293}}=\frac{310}{293} \frac{\eta_{293}}{\eta_{310}}
$$

to correct from 20 to $37^{\circ} \mathrm{C}$. The correction factor for viscosity is not available for the protein solution. Using the viscosities for water, $\eta_{293} / \eta_{310}=1.45$, gives $D_{v}=1.07 \times 10^{-6} \mathrm{~cm}^{2} / \mathrm{sec}$. For oxygen the diffusion coefficient is $1.2 \times 10^{-5} \mathrm{~cm}^{2} / \mathrm{sec}$ at $25^{\circ} \mathrm{C}$ for an $18 \%$ hemoglobin solution. Correcting to $37^{\circ} \mathrm{C}$ gives $1.6 \times 10^{-5} \mathrm{~cm}^{2} / \mathrm{sec}$. During exercise muscle temperatures may rise to $41^{\circ} \mathrm{C}$. If we take $40^{\circ} \mathrm{C}$, the values for $D_{v}$ and $D_{w}$ become $1.15 \times 10^{-6}$ and $1.97 \times 10^{-5} \mathrm{~cm}^{2} / \mathrm{sec}$ respectively.

Table 4 summarizes parameter values with references to sources and the values used by Fletcher [70]. Gonzalez-Fernandez and Atta [44] use values in the same range of values but do not include oxygen consumption in their problem. Note that Fletcher uses a value for oxygen consumption at rest that is 7 times larger than the figure reported by Folkow and Halicka [65]. The discrepancy appears to go back to Wyman's paper [12]. Wyman quotes an oxygen consumption of $4.96 \times 10^{-8} \mathrm{~mole} / \mathrm{cm}^{3} \mathrm{sec}$ for resting skeletal muscle. However, the Biological Handbook Metabolism [72] gives values that vary from $1.8 \times 10^{-9}$ for human skeletal muscle to $(6-8) \times 10^{-9}$ for rat skeletal 
muscle. Possibly the oxygen consumption for steady state contraction was mistaken for the resting condition. Wyman also used $2.8 \times 10^{-7} \mathrm{~mole} / \mathrm{cm}^{3}$ for the myoglobin concentration, whereas Wittenberg [1, Table 3] gives $5 \times 10^{-7}$. Using Wyman's figures, one calculates that the myoglobin-bound oxygen would last $2.8 \times 10^{-7} / 4.96 \times 10^{-8} \simeq 5.6 \mathrm{sec}$ at rest. Using $5 \times 10^{-7}$ mole $/ \mathrm{cm}^{3}$ for the myoglobin concentration and Folkow and Halicka's data for oxygen consumption gives a maximum for the oxygen bound to myoglobin that would last $74 \mathrm{sec}$ at rest and $8.4 \mathrm{sec}$ at maximal steady state contraction.

\section{PHYSICALLY BASED ARGUMENTS}

The purpose of this section is to see what can be learned from physical considerations.

(a) Resting Muscle. Some insight is gained by assuming the myoglobinoxygen reaction is not far from equilibrium at any point. Figure 12 shows the hemoglobin and myoglobin dissociation curves at $37^{\circ} \mathrm{C}$. Figure 13 expands the lower part of the myoglobin curve and gives a curve for mitochondrial

TABLE 4

Parameters for Modeling of Myoglobin Oxygen Diffusion in Skeletal Muscle

\begin{tabular}{|c|c|c|c|c|}
\hline Parameter & Unit & $\begin{array}{l}\text { Value for } \\
\text { muscle }^{\mathrm{a}}\end{array}$ & Reference & $\begin{array}{c}\text { Value used } \\
\text { by Fletcher [70] }\end{array}$ \\
\hline $\begin{array}{l}b(\mathrm{Mb} \\
\text { conc. })\end{array}$ & mole $/ \mathrm{cm}^{3}$ & $0.8 \times 10^{-6}$ & [1] & $(0.28-1.0) \times 10^{-6}$ \\
\hline$D_{t^{\prime}}$ & $\mathrm{cm}^{2} / \mathrm{sec}$ & $\begin{array}{c}1 \times 10^{-6} \\
\left(1.15 \times 10^{-6}\right)\end{array}$ & $\begin{array}{l}\text { Calc. from } \\
\text { [1] }\end{array}$ & $0.7 \times 10^{-6}$ \\
\hline$D_{\text {н }}$ & $\mathrm{cm}^{2} / \mathrm{sec}$ & $\begin{array}{c}1.6 \times 10^{-5} \\
\left(2.0 \times 10^{-5}\right)\end{array}$ & $\begin{array}{l}\text { Calc. from } \\
\text { [1] }\end{array}$ & $1.5 \times 10^{-5}$ \\
\hline$\alpha_{3}$ & mole $/ \mathrm{cm}^{3}$ Torr & $1.23 \times 10^{-9}$ & {$[71]$} & $1.32 \times 10^{-9}$ \\
\hline$k_{1}$ & $\mathrm{~cm}^{3} /$ molesec & $\begin{array}{c}24 \times 10^{9} \\
\left(25.5 \times 10^{9}\right)^{b}\end{array}$ & {$[1]$} & $24 \times 10^{9}$ \\
\hline$k_{2}$ & $\sec ^{-1}$ & $\begin{array}{c}65 \\
(74)^{b}\end{array}$ & {$[1]$} & 65 \\
\hline $\begin{array}{l}\mathrm{O}_{2} \text { consumption } \\
\text { (resting) }\end{array}$ & mole $/ \mathrm{cm}^{3} \mathrm{sec}$ & $6.8 \times 10^{-9 c}$ & {$[65]$} & $5 \times 10^{-8}$ \\
\hline $\begin{array}{l}\text { Max. steady state } \\
\text { exercise }\end{array}$ & & $5.95 \times 10^{-8 c}$ & {$[65]$} & - \\
\hline
\end{tabular}

${ }^{\mathrm{a}} \mathrm{At}-37^{\circ} \mathrm{C}$ (values in parentheses at $40^{\circ} \mathrm{C}$ ).

${ }^{\mathrm{b}}$ Extrapolated from linear plot of $k$ versus $1 / T$.

${ }^{c}$ Folkow and Halicka give 0.91 and $8\left(\mathrm{ml} \mathrm{O}_{2}\right) /(100 \mathrm{~g})$ min for oxygen consumption in cat soleus at rest and at maximal activity. 


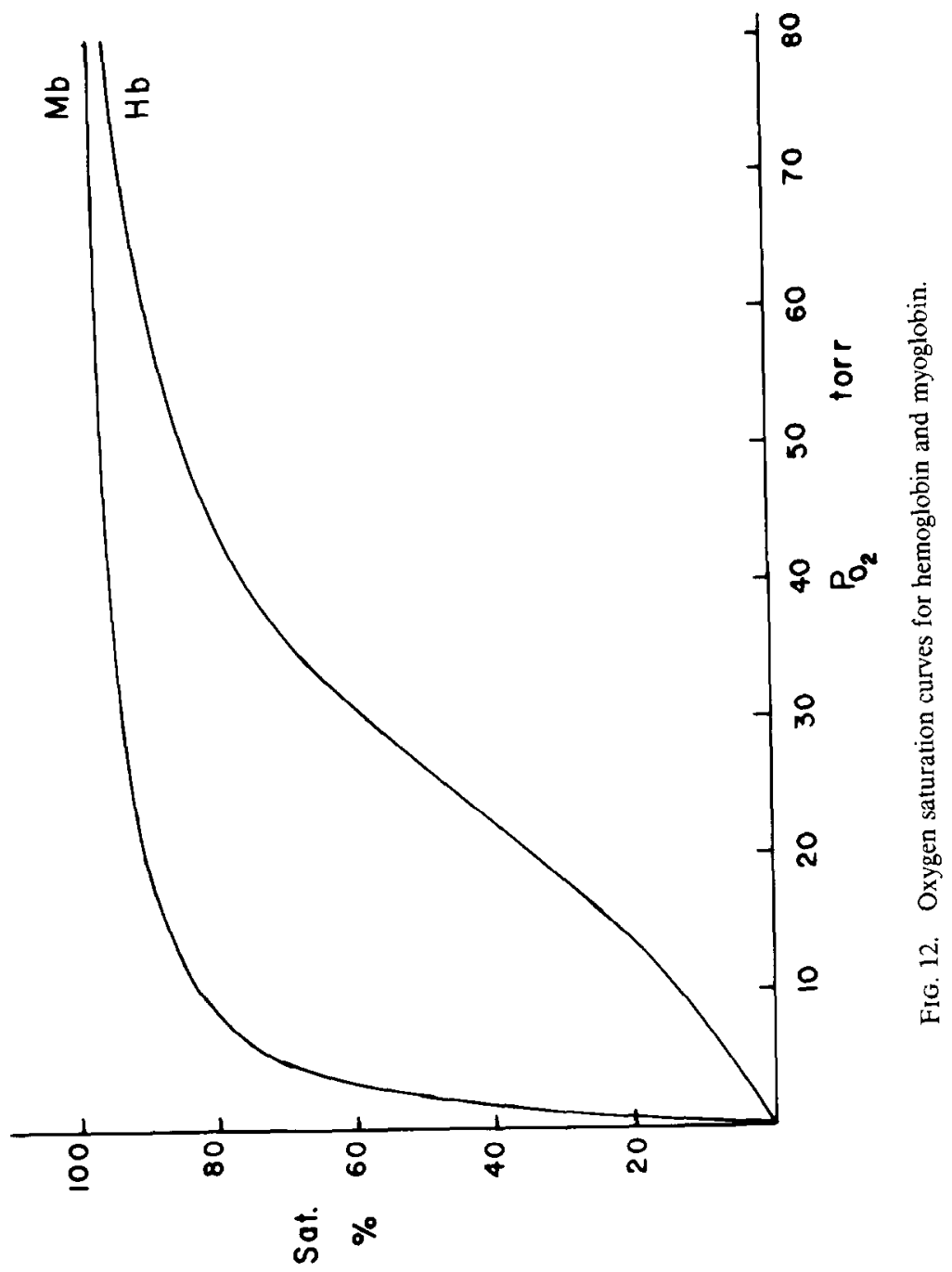




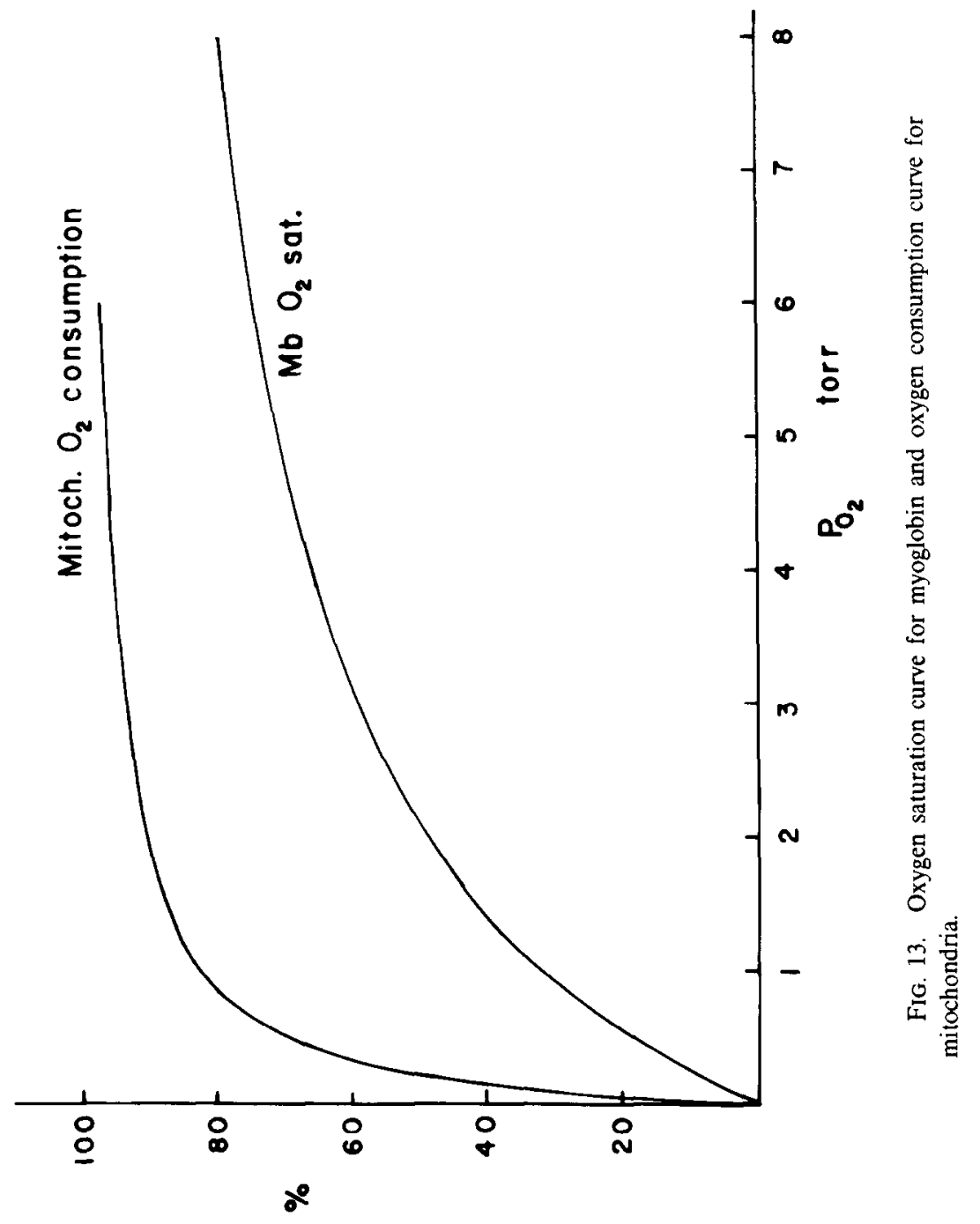


oxygen consumption assuming a Michaelis-Menten type of expression with $K_{m}=0.2$ Torr for $P_{\mathrm{O}_{2}}$ :

$$
\frac{q}{Q_{M}}=\frac{P_{\mathrm{O}_{2}}}{0.2+P_{\mathrm{O}_{2}}} .
$$

A number of points are obvious from Figures 12 and 13:

(i) As $P_{\mathrm{O}_{2}}$ falls from 100 to 40 Torr from the arterial to the venous end of the capillary, any myoglobin next to the capillary must remain practically saturated.

(ii) If the $P_{\mathrm{O}_{2}}$ at the mitochondria is about 3 Torr or more, there can be very little contribution from facilitated diffusion on myoglobin, because myoglobin is still $60 \%$ saturated at 3 Torr. As $P_{\mathrm{O}_{2}}$ falls towards 0.5 Torr, facilitated diffusion must increase but oxygen consumption falls little. Thus the myoglobin could provide a flux buffer as the $P_{\mathrm{O}_{2}}$ at the mitochondria falls.

(b) Contracting Muscle. In maximally contracting soleus the $P_{\mathrm{O}_{2}}$ at the venous end of the capillaries falls only to $17-18$ Torr, so the adjacent myoglobin must remain about $90 \%$ saturated. Oxygen consumption goes up by a factor of 8.75 . Blood flow increases by the opening of more capillaries, decreasing the mean diffusion path. The flow per capillary actually decrcases during the contractile phase in a repetitively contracting muscle. For the gastrocnemius the venous $P_{\mathrm{O}_{2}}$ falls to about 10 Torr in maximum activity. The $P_{\mathrm{O}_{2}}$ at the mitochondria must fall as the oxygen consumption increases.

During contraction the muscle fibers shorten and swell, so there must be some movement of the cytosol back and forth between the myofibrils, suggesting that convective mixing may well contribute to the oxygen transport by way of myoglobin. The diffusion coefficient of myoglobin is so low that a little convective mixing could have a significant effect. This would be difficult to model, although it might be treated as an increase in $D_{l}$.

It is worth noting that although the reaction between myoglobin and oxygen is temperature dependent, it is practically insensitive to changes in $\mathrm{pH}$ or salt composition [73], so that changes in the intracellular $\mathrm{pH}$ during contraction of the muscle cell cannot affect the myoglobin-oxygen dissociation curve. The curve of oxygen saturation of myoglobin as a function of $P_{\mathrm{O}_{2}}$ (Figure 12) is shifted to the right as the temperature increases [73].

(c) Reaction Rates and Diffusion Rates. What of the transients during repetitive contraction? Blood flow in capillaries decreases during the contractile phase and increases again during relaxation, so the $P_{\mathrm{O}_{2}}$ at the venous end of the capillaries must cycle up and down. However, the change in saturation of the myoglobin adjacent to the venous end of the capillary is small, so there may not be large transients. 
TABLE 5

Rate Constants for Reaction of $\mathrm{Mb}$ with $\mathrm{O}_{2}$ at $37^{\circ} \mathrm{C}$ at fixed $P_{\mathrm{O}_{2}}$

\begin{tabular}{l|lccr}
\hline$P_{\mathrm{O}_{2}}($ Torr $)$ & \multicolumn{1}{|c}{1} & 10 & 40 & \multicolumn{1}{c}{100} \\
\hline$k_{1} w^{\prime}=k_{1} \alpha_{s} P_{\mathrm{O}_{2}}\left(\mathrm{sec}^{-1}\right)$ & 31.68 & 316.8 & 1267.2 & 3168 \\
$k_{2}\left(\mathrm{sec}^{-1}\right)$ & 65 & 65 & 65 & 65 \\
$k_{1} w+k_{2}\left(\mathrm{sec}^{-1}\right)$ & 96.7 & 381.8 & 1332 & 3233 \\
\hline
\end{tabular}

Nonetheless it is worthwhile to compare reaction rates and the diffusion rate of myoglobin to see if the difference in forward and backward reaction rates can give a valving effect. Consider what happens if the $P_{\mathrm{O}_{2}}$ is suddenly changed from 40 to 10 or 1 Torr and then the reverse. The rate of change of the oxymyoglobin is given by

$$
\frac{d v}{d t}=k_{1}(b-v) w-k_{2} v=k_{1} b w-\left(k_{1} w+k_{2}\right) v .
$$

Table 5 gives rate constants for the forward and backward reactions at a number of fixed $P_{\mathrm{O}_{2}}$ 's. Note that the forward rate is much faster than the backward rate at $P_{\mathrm{O}_{2}}$ 's above 10 Torr. If $w$ is changed suddenly and then held constant, Equation (55) is a linear equation with time constant $k_{1} w+k_{2}$, which is also given in Table 5. Table 6 gives half-times and times to $90 \%$ completion of reaction for cycling between 10 and 40 and between 1 and 40 Torr. Obviously the on reaction is faster than the off reaction. However, at contraction rates in the range $60-600 / \mathrm{min}$, i.e., a cycle time of $1-0.1 \mathrm{sec}$, both on and off reactions are fast enough to follow the change in $P_{\mathrm{O}_{2}}$. It would take contraction frequencies greater than $100 / \mathrm{sec}$ before the difference between on and off rates would lead to a valving effect, i.e., forward rate fast enough to come close to equilibrium in a cycle time, but backward rate not fast enough to reach equilibrium, so that the mean oxygen saturation must be closer to that at the high $P_{\mathrm{O}_{2}}$. Interestingly, the flight muscles of

TABLE 6

Half-Times and Times to $90 \%$ Completion for Shilts in $P_{\mathrm{O}_{2}}$

\begin{tabular}{cll}
\hline Shift & \multicolumn{1}{c}{$\begin{array}{c}t_{1 / 2} \\
(\mathrm{sec})\end{array}$} & $\begin{array}{c}t_{90 \%} \\
(\mathrm{sec})\end{array}$ \\
\hline $1 \rightarrow 40$ & 0.00052 & 0.00173 \\
$10 \rightarrow 40$ & & \\
$40 \rightarrow 10$ & 0.00182 & 0.006 \\
$40 \rightarrow 1$ & 0.0072 & 0.0238 \\
\hline
\end{tabular}


insects and hearts of small mammals and birds, which have contraction frequencies as high as $300 / \mathrm{sec}$, have low levels of myoglobin. The highest levels of myoglobin in nondiving animals are found in muscles that undergo slow repeated contractions of high force at rates on the order of $1 / \sec [1]$.

For comparison with the reaction rates, the time constant for diffusion of myoglobin is $D_{v} / L^{2}$, giving a $t_{90}$ of $0.58 \mathrm{sec}$ for $5 \mu \mathrm{m}$ and 0.023 for $1 \mu \mathrm{m}$.

\section{MODELS OF OXYGEN DISTRIBUTION}

\section{PREVIOUS WORK}

Most of the work done until quite recently on modeling blood flow and oxygen delivery to muscle did not specifically include myoglobin in the model. For recent reviews see Fletcher [74] and Kreuzer [75]. A recent study which did include myoglobin was that of Fletcher [70]. Fletcher used as a model a cylindrical tissue domain $300 \mu \mathrm{m}$ long centered on a capillary; he assumed that myoglobin was diffusible throughout the tissue domain and that oxygen consumption was constant and uniformly distributed throughout the tissue, and he used a value close to the maximal oxygen consumption of soleus during steady state exercise. Mainwood and Rakusan [76] compared ATP profiles in a Krogh type model with uniform distribution of mitochondria [70] and one in which mitochondria are clustered near capillaries and ATP diffuses into the interior of the cell, but they did not consider the possible effects of myoglobin.

\section{MODELS}

In this section let us try to devise some models that may give insight into what goes on in red muscle cells that are engaged in repetitive contraction.

To emphasize the realities with which we shall have to cope, Figure 11 is an idealized summary of the structure of a muscle cell in cross-section. In addition to the features obvious in this cross-section, remember that the capillaries don't run a straight course but wander back and forth as though they were trying to cover the entire surface. The major features one might want to include in models are the subsarcolemmal mitochondria and the bands of intermyofibrillar mitochondria; also the banding pattern may shift as one moves along the fiber.

The structural characteristics of muscle and of its blood flow suggest that the domain or unit of modeling should be the individual muscle fiber with its surrounding capillary flow and not a single capillary with a surrounding tissue cylinder. To bring out the effects of some of these features I propose we examine the following models.

Figure 14(a) and (b) show two models which would show the effects of the patterned distribution of mitochondria. These are idealized cylinders square 


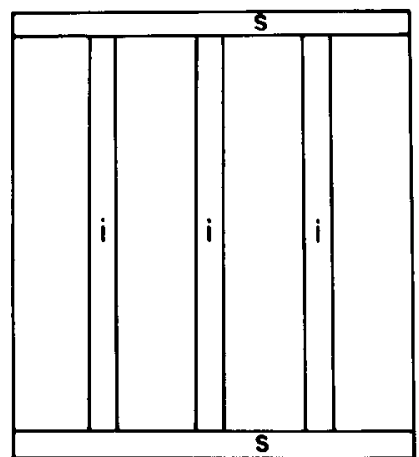

(a)

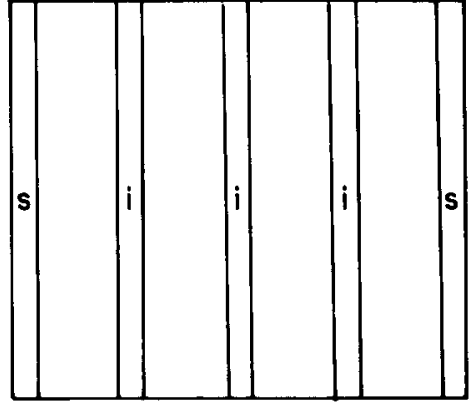

(b)

FIG. 14. Diagrams of cross-sections of models proposed to study function of myoglobin in muscle fibers: $i$, intermyofibrillar mitochondria; $s$, subsarcolemmal mitochondria.

in cross-section; oxygen consumption occurs only in the bands of intermyofibrillar and subsarcolemmal mitochondria. Assume a uniform concentration of myoglobin which can diffuse freely throughout these cells. The boundary conditions are that $P_{\mathrm{O}_{2}}$ is uniform around the perimeter of the cells. In a first model using these structural features, set the $P_{\mathrm{O}_{2}}$ at constant level or have it fluctuate sinusoidally so as to reflect the changes in $P_{\mathrm{O}_{2}}$ at the

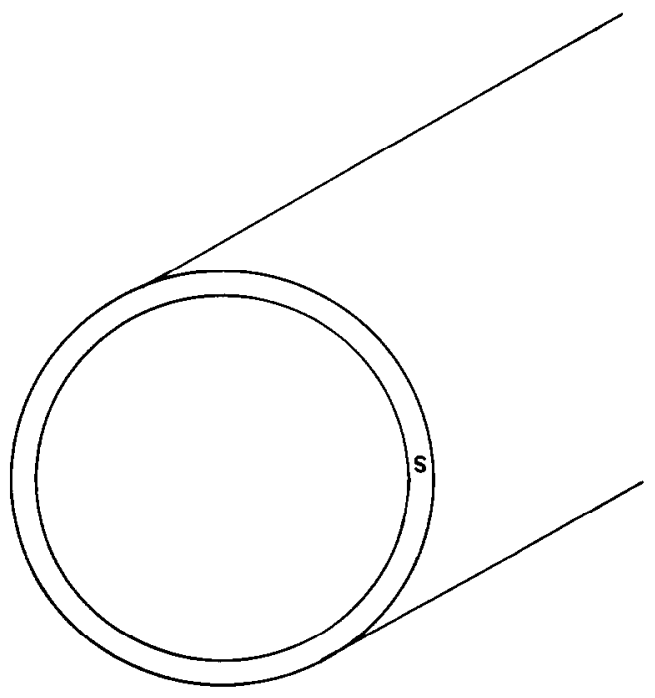

FIG. 15. Model with cylindrical symmetry; subsarcolemmal mitochondria and uniformly distributed mitochondria inside muscle cell. 
venous end of a capillary during repetitivc contraction. If this is manageable, the next step will be to introduce the blood flow along the longitudinal direction as a thin film flowing down the length of such a fiber.

Another model, to show the effect of the subsarcolemmal mitochondria, is diagrammed in Figure 15. In this cylindrical muscle cell, assume the oxygen consumption is uniformly distributed in the interior of the cell, but retain the subsarcolemmal mitochondria. Again, in a first study the $P_{\mathrm{O}_{2}}$ could be taken to be uniform around the periphery but changing sinusoidally with time to simulate the effect of contraction; later, blood flow in the longitudinal direction could be introduced.

\section{GLOSSARY OF SYMBOLS}

$\mathrm{Mb}, \mathrm{Hb}=$ myoglobin and hemoglobin, respectively

$x=$ distance into a membrane, from left surface, $\mathrm{cm}$

$L=$ thickness of membrane, $\mathrm{cm}$

$u=$ concentration of non-oxygen-carrying myoglobin or hemoglobin binding sites for oxygen, mole $/ \mathrm{cm}^{3}$

$v=$ concentration of oxygen-carrying binding sites, mole $/ \mathrm{cm}^{3}$

$b=u+v$, a constant

$w=$ concentration of free oxygen, mole $/ \mathrm{cm}^{3}$

$D_{u}, D_{v}, D_{u^{\prime}}=$ diffusion coefficients for $u, v$ and $w$ respectively, $\mathrm{cm}^{2} / \mathrm{sec}$.

$k_{1}=$ rate constant for formation of oxymyoglobin, i.e.

$$
\mathrm{Mb}+\mathrm{O}_{2} \stackrel{k_{1}}{\rightarrow} \mathrm{MbO}_{2},
$$

$\mathrm{cm}^{3} /$ mole sec.

$k_{2}=$ rate constant for dissociation of oxymyoglobin, i.e.

$$
\mathrm{MbO}_{2} \stackrel{k^{2}}{\rightarrow} \mathrm{Mb}+\mathrm{O}_{2},
$$

$\sec ^{-1}$

$k_{1}^{i}=$ forward rate constant for oxygen-binding sites of hemoglobin for addition of $i$ th oxygen, the intrinsic forward rate constant, $\mathrm{cm}^{3} /$ molesec

$k_{2}^{i}=$ backward intrinsic rate constant for dissociation of $i$ th oxygen from oxyhemoglobin

$J_{t}=$ total flux of oxygen crossing membrane, constant in the steady state, $\mathrm{mole} / \mathrm{cm}^{2} \mathrm{sec}$

$J_{D}=$ diffusive flux of oxygen

$J_{F}=$ facilitated flux of oxygen, $J_{t}=J_{F}+J_{D}$ 
$P_{0}, P_{L}=$ partial pressures of oxygen at left and right sides of membrane, respectively (the units, Torr, are practically the same as $\mathrm{mm} \mathrm{Hg}$ ) $\boldsymbol{\alpha}_{s}=$ solubility of oxygen, mole $/ \mathrm{cm}^{3}$ Torr $w_{0}-\alpha_{S} P_{0}$

$G=$ conductance of surface layer, mole $/ \mathrm{cm}^{2} \sec$ Torr

$\eta=$ viscosity

$q=$ oxygen consumption by muscle as function of partial pressure of oxygen $\left(P_{\mathrm{O}_{2}}\right)$, mole $/ \mathrm{cm}^{3} \mathrm{sec}$

$Q_{m}=$ maximal oxygen consumption:

$$
q=Q_{m} \frac{P_{\mathrm{O}_{2}}}{P_{\mathrm{O}_{2}}+K_{m}}
$$

$K_{m}=$ partial pressure of oxygen at which $q=Q_{m} / 2$

\section{DIMENSIONLESS VARIABLES}

$$
\begin{aligned}
y & =x / L \\
V & =v / b \\
W & =w / w_{0} \\
\alpha & =k_{2} L^{2} / D_{v} \\
\beta & =b D_{v} / D_{u} W_{0} \\
\gamma & -k_{1} w_{0} / k_{2} \\
\epsilon_{1} & =1 / \alpha \beta \gamma \\
\epsilon_{2} & =1 / \alpha \gamma \\
\mu & =1 / \gamma
\end{aligned}
$$

This review was written at the Fogarty International Center in 1983 during my tenure as a Fogarty Scholar. I want to thank Drs. Beaubien and Condliffe and the staff of the Fogarty International Center for their gracious hospitality and for the secretarial and administrative support which made this task so much easier than it would have been otherwise.

I want to thank Drs. R. Aris, J. Garner, J. Fletcher, and J. GonzalezFernandez for reading the first draft of this review and wish to express my particular thanks to Dr. Gonzalez-Fernandez for his careful and incisive critique.

\section{REFERENCES}

1 J. B. Wittenberg, Myoglobin-facilitated oxygen diffusion: Role of myoglobin in oxygen entry into muscle, Physiol. Rev. 50:559-636 (1970).

2 F. Kreuzer, Facilitated diffusion of oxygen and its possible significance; a review, Respir. Physiol. 9:1-30 (1970).

3 J. S. Schultz, J. O. Goddard, and S. R. Suchdeo, Facilitated transport via carrier-mediated diffusion in membranes. Part $\mathrm{I}$. Mechanistic aspects, experimental systems and characteristic regimes, $A I C h E J$. 20:417-445 (1974). 
4 J. D. Goddard, J. S. Schultz, and S. R. Suchdeo, Facilitated transport via carrier-mediated diffusion in membranes. Part II. Mathematical aspects and analyses, $A I C h E J$. 20:625-645 (1974).

5 R. J. W. Roughton, Diffusion and chemical reaction velocity as joint factors in determining the rate of uptake of oxygen and carbon monoxide by the red blood corpuscle, Proc. Roy. Soc. London Ser. B 3:1-36 (1932).

6 G. A. Millikan, Muscle-hemoglobin, Physiol. Rev. 19:503-523 (1939).

7 A. Klug, F. Kreuzer, and F. J. W. Roughton, The diffusion of oxygen in concentrated hemoglobin solutions, Helv. Physiol. Pharm. Acta 14:121-128 (1956).

8 A. Klug, F. Kreuzer, and F. J. W. Roughton, Simultaneous diffusion and chemical reaction in thin layers of hemnglohin solution, Proc. Roy. Soc. London Ser. B $145: 452-472(1956)$.

9 J. B. Wittenberg, Oxygen transport: A new function proposed for myoglobin, Biol. Bull. 117:402 (1959).

10 P. F. Scholander, Oxygen transport through hemoglobin solutions, Science 131:585-590 (1960).

11 E. Hemmingsen and P. F. Scholander, Specific transport of oxygen through hemoglobin solutions, Science 132:1379-1381 (1960).

$12 \mathrm{~J}$. Wyman, Facilitated diffusion and the possible role of myoglobin as a transport mechanism, J. Biol. Chem. 241:115-121 (1966).

13 J. B. Wittenberg, The molecular mechanism of hemoglobin-facilitated oxygen diffusion, J. Biol. Chem. 241:104-114 (1966).

14 J. A. Jacquez, H. Kutchai, and E. Daniels, Hemoglobin-facilitated diffusion of oxygen: Interfacial and thickness effects, Resp. Physiol. 15:166-181 (1972).

15 D. Yung and R. B. Probstein, Similarity conditions in facilitated transport, J. Phys. Chem. 77:2201-2205 (1973).

$16 \mathrm{~J}$. Gonzalez-Fernandez and S. E. Atta, Transport of oxygen in solutions of myoglobin and hemoglobin, Math. Biosci. 54:265-290 (1981).

17 F. Kreuzer and L. J. C. Hoofd, Facilitated diffusion of oxygen in the presence of hemoglobin, Resp. Physiol. 10:542-558 (1970).

18 H. Kutchai, J. A. Jacquez, and F. J. Mather, Nonequilibrium facilitated oxygen transport in hemoglobin solution, Biophys. J. 10:38-54 (1970).

19 H. Kutchai, Numerical study of oxygen uptake by layers of hemoglobin solution, Resp. Physiol. 10:223-284 (1970).

20 J. D. Murray, On the molecular mechanism of facilitated oxygen diffusion by haemoglobin and myoglobin, Proc. Roy. Soc. London Ser. B 178:95-110 (1971).

21 P. J. Mitchell and J. D. Murray, Facilitated diffusion: The problem of boundary conditions, Biophysik 9:177-190 (1973).

22 H. Kutchai, Role of red cell membrane in oxygen uptake, Resp. Physiol. 23:121-132 (1975).

23 S. I. Rubinow and M. Dembo, The facilitated diffusion of oxygen by hemoglobin and myoglobin, Biophys. J. 18:29-42 (1977).

24 M. Weingarden, H. Mizukami, and S. A. Rice, Transient effects on the initial rate of oxygenation of red blood cells, Bull. Math. Biol. 44:119-134 (1982).

25 M. Weingarden, H. Mizukami, and S. A. Rice, Factors defining the rate of oxygen uptake by the red blood cell, Bull. Math. Biol. 44:135-147 (1982).

26 J. H. Meldon, K. A. Smith, and C. K. Colton, Analysis of 2,3-diphosphoglyceratemediated, hemoglobin-facilitated oxygen transport in terms of the Adair reaction 
mechanism in Oxygen Transport to Tissue (H. I. Bicher and D. F. Bruley, Eds.), Plenum, New York, 1973, pp. 199-205.

27 P. Stroeve, K. A. Smith, and C. K. Colton, Facilitated transport of oxygen in blood in terms of the Adair mechanism and the effect of 2,3-diphosphoglycerate, Bibl. Anat. 13:173-174 (1975).

28 G. H. Gijsbers and H. J. Van Ouwerkerk, Boundary layer resistance of steady-state oxygen diffusion facilitated by a four-step chemical reaction with hemoglobin in solution, Pflügers Arch. 365:231-241 (1976).

29 R. E. Hanna and J. B. Garner, An analysis of facilitated-diffusion problems, Math. Biosci. 63:9-20 (1983).

30 R. Bellman and R. Kalaba. Quasilinearization and Nonlinear Boundary-Value Problems, American Elsevier, New York.

31 K. A. Smith, J. H. Meldon, and C. K. Colton, An analysis of carrier-facilitated transport, AIChE J. 19:102-111 (1973).

32 S. R. Suchdeo and J. S. Schultz, Mathematical approaches to the analysis of facilitated transport phenomenon in membranes, Chem. Eng. Progr. Symp. Ser. 67 (114):165-173 (1971).

33 J. D. Cole, Pcrturbation Methods in Applied Mathematics, Blaisdell, 1968.

34 W. Moll, The diffusion coefficient of myoglobin in muscle homogenate, Pflügers Arch. 299:247-251 (1968).

35 B. A. Wittenberg and J. B. Wittenberg, Role of myoglobin in the oxygen supply to red skeletal muscle, J. Biol. Chem. 250:9038-9043 (1975).

36 J. D. Murray, On the role of myoglobin in muscle respiration, J. Theoret. Biol. 47:115-126 (1974).

37 B. A. Taylor and J. D. Murray, Effect of the rate of oxygen consumption on muscle, $J$. Math. Biol. 4:1-20 (1977).

38 R. P. Cole, B. A. Wittenberg, and P. R. B. Caldwell, Myoglobin function in the isolated flurocarbon-perfused dog heart, Amer. J. Physiol. 234:H567-H572 (1978).

39 R. P. Cole, Myoglobin function in exercising skeletal muscle, Science 216:523-525 (1982).

40 T. E. J. Gayeski and C. R. Honig, Myoglobin saturation and calculated $P_{\mathrm{O}_{2}}$ in single cells of resting gracilis muscle, in Oxygen Transport to Tissue - III (I. A. Silver, M. Erecinska, and H. I. Bicher, Eds.), Plenum, New York, 1977, pp. 77-84.

41 V. Schwarzmann and W. A. Grunewald, Myoglobin- $\mathrm{O}_{2}$ saturation profiles in muscle sections of chicken gizzard and the facilitated $\mathrm{O}_{2}$-transport by $\mathrm{Mb}$, in Oxygen Transport to Tissue-III (I. A. Silver, M. Erecinska, and H. I. Bicher, Eds.), Plenum, New York, 1977, pp. 301-310.

42 J. deKoning. L. J. C. Hoofd, and F. Kreuzer, Oxygen transport and the function of myoglobin, Pflügers Arch. 389:211-217 (1981).

43 L. Hoofd and F. Kreuzer, A new mathematical approach for solving carrier-facilitated steady-state diffusion problems, J. Math. Biol. 8:1-13 (1979).

44 J. M. Gonzalez-Fernandez and S. E. Atta, Facilitated transport of oxygen in the presence of membranes in the diffusion path, Biophys. J. 38:133-141 (1982).

45 W. Bloom and D. W. Fawcett, A Textbook of Histology, W. B. Saunders, Philadelphia, 1968.

46 D. S. Smith, Muscle, Academic, New York, 1972.

47 C. Franzini-Armstrong, Membranous systems in muscle fibers, in The Structure and Function of Muscle (G. H. Bourne, Ed.), 2nd ed., Vol. II, Academic, 1973, Part 2, Chapter 9, pp. 532-619. 
48 H. A. Padykula and G. F. Gauthier, Morphological and cytochemical characteristics of fiber types in normal mammalian skeletal muscle, in Exploratory Concepts in Muscular Dystrophy and Related Disorders (A. T. Milhorat, Ed.), Excerpta Med. Found., No. 147, 1967, pp. 117-128.

49 G. F. Gauthier, The ultrastructure of three fiber types in mammalian skeletal muscle, in The Physiology and Biochemistry of Muscle as a Food, Vol. 2 (E. J. Briskey, R. G. Cassens, and B. B. Marsh, Eds.), Univ. of Wisconsin Press, Madison, 1970, Chapter 7.

50 H. Hoppcler, P. Lüthi, H. Claassen, E. R. Wcibcl, and H. Howald, The ultrastructurc of the normal human skeletal muscle, Pflügers Arch. 344:217-232 (1973).

51 D. A. Krieger, C. A. Tate, J. McMillan-Wood, and F. W. Booth, Populations of rat skeletal muscle mitochondria after exercise and immobilization, J. Appl. Physiol. 48:23-28 (1980).

52 P. D. Gollnick and D. W. King, Effect of exercise and training on mitochondria of rat skeletal muscle, Amer. J. Physiol. 216:1502-1509 (1969).

53 K. H. Kiesshing, K. Piehl, and C. G. Lundquist, Effect of physical training on ultrastructural features in human skeletal muscle, in Muscle Metabolism during Exercise (B. Pernow and B. Saltin, Eds.), Plenum, New York, 1971, pp. 97-101.

54 J. A. Jacquez, Respiratory Physiology, Hemisphere-McGraw-Hill, 1979.

55 F. F. Jöbsis, Basic processes in cellular respiration, in Handbook of Physiology, Section 3: Respiration, Vol. I, Amer. Physiol. Soc., Washington, 1964.

56 B. Chance, Reaction of oxygen with the respiratory chain in cells and tissues, J. Gen. Physiol. 49(1, Part 2):163-188 (1965).

57 O. Barzu and M. Satre, Determination of oxygen affinity of respiratory systems using oxymyoglobin as oxygen donor, Anal. Biochem. 36:428-433 (1970).

58 O. Hudlicka, Muscle Blood Flow, Swets and Zeitlinger, Amsterdam, 1973.

59 F. C. A. Romanul, Capillary supply and metabolism of muscle fibers, Arch. Neurol. 12:497-509 (1965).

60 S R Kayar and N. Banchero, Distribution of capillaries and diffusion distances in guinea pig myocardium, Pflügers Arch. 396:350-352 (1983).

61 J. Keul, E. Doll, and D. Keppler, Energy Metabolism of Human Muscle, Univ. Park Press, Baltimore, 1972.

62 E. Asmussen, Muscular Exercise, Handbook of Physiology, Section 3: Respiration, Vol. II, Amer. Physiol. Soc., Washington, 1965, pp. 939-978.

63 B. R. Duling and R. M. Berne, Longitudinal gradients in periarteriolar oxygen tension, Circul. Res. 27:669-678 (1970).

64 B. R. Duling and R. N. Pittman, Oxygen tension: Dependent or independent variable in local control of blood flow?, Fed. Proc. 34:2012-2019 (1975).

65 B. Folkow and H. D. Halicka, A comparison between "red" and "white" muscle with respect to blood supply, capillary surface area and oxygen uptake during rest and exercise, Microvasc. Res. 1:1-14 (1968).

66 N. T. James, Histochemical demonstration of myoglobin in skeletal muscle fibres and muscle spindles, Nature 219:1174-1175 (1968).

67 S. Morita, R. G. Cassens, and E. J. Briskey, Localization of myoglobin in striated muscle of the domestic pig; benzidine and $\mathrm{NADH}_{2}$-TR reactions, Stain Techn. 44:283-286 (1969).

68 O. J. Livingston, G. N. LaMar, and W. D. Brown, Myoglobin diffusion in bovine heart muscle, Science 220:71-73 (1983).

69 V. Riveros-Moreno and J. B. Wittenberg, The self-diffusion coefficients of myoglobin and hemoglobin in concentrated solutions, J. Biol. Chem. 247:895-901 (1972). 
70 J. E. Fletcher, On facilitated oxygen diffusion in muscle tissues, Biophys. J. 29:437-458 (1980).

71 J. Grote and G. Thewe, Die Bedingungen für die Sauerstoffversorgung des Herzmuskelgewebes, Pflügers Arch. 276:142-165 (1962).

72 P. L. Altman and D. S. Dittmer (Eds.), Metabolism, Biol, Handbooks, Fed. Amer. Soc. Exptl. Biol., Bethesda, Md., 1968.

73 E. Antonini, Interrelationship between structure and function in hemoglobin and myoglobin, Physiol. Rev. 45:123-170 (1965).

74 J. E. Fletcher, Mathematical modeling of the microcirculation, Math. Biosci. 38:159-202 (1978).

75 F. Kreuzer, Oxygen supply to tissues: The Krogh model and its assumptions, Experientia 38:1415-1426 (1982).

76 G. W. Mainwood and K. Rakusan, A model for intracellular energy transport, Canad. J. Physiol. Pharmacol. 60:98-102 (1982). 